\title{
Exploring the Organized Realities and Education Logics In the Qualification Training System for Level 2-Sport-for-all-Coach Through the Analysis of Coordination Process
}

\author{
Juyoung Ryou \\ Seoul National University
}

\begin{abstract}
[Purpose] There are two purposes of this study; First is to investigate the reality of curriculum in the qualification system through the coordination process between participants' experiences and institutional texts. Second is to identify the light and shade of the educational logics underlying the certificate courses of Level 2-sport-for-all-coach. [Methods] By relying on the institutional ethnography approach(Smith, 2005), the data were collected through on-site materials and semi-structural interviews with seven coaches who participated in the qualification programmes after 2015 system revision. The data were analyzed by mapping the social organization. [Results] The analysis shows two key findings. First, participants faced inconsistencies with institutional texts in the subcategories of qualification system and experienced (self-)rationalization process including doubt, complaint, acceptance and compromise toward the system. Second, Performance pedagogy and Craft pedagogy were operating at the root of the current qualification system, and the two logics led to the fundamental limitations(unlinked educational content, passive educational activity, and unsystematic educational operation) for the improvement of system. [Conclusions] The activation of the retrospective approach to distinguish the pros and cons of various educational logics was suggested. These findings are expected to provide useful implications for building the future framework to educate sport-coaches more systematically.
\end{abstract}

Key words: Qualification System, Curriculum, Coordination, Organized reality, Educational Logic

\section{서 론}

(생활스포츠) 강사들이 처우개선을 요구하며 기자회견을 열었다. 이날 $\mathrm{OOO}$ 강사는 "우리는 $(\cdots)$ 국가자격증과 수상안전요원 자격 증을 갖춘 전문직이다. 우리의 전문성을 인정하리"고 요구했다 (OhmyNews, 2018.12.05).

논문 투고일 : 2021. 01. 06.

논문 수정일 : 2021. 02. 25.

게재 확정일 : 2021. 03. 17.

* 교신저자 : 유주영(ryoua120@snu.ac.kr).

* 본고는 2020.11.13 실시된 〈2020 Global Sport Science Virtual Conference〉의 발표문을 수정·보완한 것임.
“우리의 전문성을 인정하라"는 생활스포츠지도자들 의 아우성은 어제 오늘 이야기가 아니다. 그간 이들의 외침은 고용불안(Sea, Kim \& Shin, 2014), 저임금(Kim, 2004), 열악한 근무환경(Lee \& Yoo, 2001), 낮은 직무만 족도(Won, Lee \& Yoo, 2001), 높은 이직률(Jung, 2000) 등 의 형태로 대두되었고, 그 쟁점의 기저에는 지도자의 '전문성 결여'와 이를 바라보는 '사회의 부정적 인식'이 자리매김해왔다(Chin, Kim \& Lee, 2015; Eun, 2017; Shim, 2012; Jung, 2019; Kim \& Lee, 2003).

만일 생활스포츠지도자들의 전문성이 결여되어있 고 이를 향한 외부의 시선이 부정적이라면, 어찌하여 
대다수의 지도자들이 대학교육을 받고, 국가자격을 취 득하였음에도 전문성을 발휘하지 못한 것인지, 전문인 으로서의 역량배양, 제고, 강화를 공표해온 자격개편 (Ministry of Culture, Sports and Tourism: MCST, 2013.07.01; 2014) 이후에도 전문성을 향한 우려의 목소 리(Chin, Kim\& Lee, 2015; Eun, 2017; Jung, 2019)가 끊이 지 않는 연유가 무엇인지, 나아가 전문성이라는 강력한 레토릭(rhetoric)이 학문의 영역을 벗어난 실천의 국면 에서 왜 이리도 무기력한 것인지(Jung, 2020), 면밀히 검 토될 필요가 있다. 교육의 질이 교수자의 질을 넘지 못 하듯, 생활스포츠지도자의 전문성을 고려치 않고 생활 체육의 질적 향상을 기대할 수 없기 때문이다. 특히 생 활체육의 목적이 국민의 건강유지를 통한 의료비용 절 감, 행복지수 향상, 운동가치 향유에 놓여있고(MCST, 2018a), 이를 위한 스포츠코칭이 모든 연령에 걸친 총체 적 교육활동이라는 점에서(Choi, 2018), 앞선 '전문성 결여'의 화두는 결코 간과되어선 안 될 중대사안이다.

이와 같이 생활스포츠지도사의 '전문성'에 역점을 둔 연구의 흐름은 크게 세 갈래로 분류될 수 있다. 첫째, 지도자의 전문성을 처우개선 및 지위향상과 연결하여 바라보는 접근이다(Eun, 2017; Shon et al., 2016; Kim, 2004; Kim \& Chung, 1996). 둘째, 지도자에게 요구되는 전문성을 하위요인으로 범주화한 뒤, 다른 변인과의 관 계를 분석하는 접근이다(Chin, Kim \& Lee, 2015; Choo, 2017; Kim; 2005; 2011; Kim, 2017). 셋째, 자격제도 관련 법률 및 정책을 고찰하거나, 국외 및 유사분야의 검증 체제를 비교·분석하는 접근이다(Cho, 2008; 2016; Cho \& Kwon, 2011; Oak, 2007; Park \& Park, 2014).

이중 자격제도에 방점을 찍은 연구물을 연대별로 살 펴보면, 2000년대에는 자격의 현황, 명칭(용어), 등급, 개편의 필요성, 개선방향 관련 이슈가 다루어졌다 (Kwon, 2005; Oh, 2000; Park, 2008), 2010년대 초반에는 노동시장의 불균형, 법률검토, 지위향상 등의 키워드 가 고찰되었다(Kwon, 2017, p. 50). 2015년 이후에는 제 도의 쟁점 및 정책의 방향, 교육내용, 강사전문성, 실습 효과, 신분안정 관련 주제가 논의되고 있다(Jung, Lee \& Lee, 2019, p. 145; Kim, 2020, p. 115).

이러한 기조의 연구들은 지도자의 전문성 신장을 위 해 처우개선이 함께 이뤄져야 함을 공론화하고, 바람직 한 전문성을 규정하며, 관련 법령의 보완을 제안하는데
공헌하였다. 하지만, 당위적 ‘처방’을 공급하기에 앞서, 문제자체에 진지한 관심을 기울이려는 노력은 상대적 으로 미흡하였다. 구체적으로 말하여, 전향(前向)의 관 점1)에서 처우개선 방안, 올바른 덕목 및 자질 규정, 법 률·제도 정비와 같은 다양한 해법을 주문해온데 비해, 모종의 처방을 제공하기 전, 자격제도 내 교육과정을 '진단'하는 후향(後向)의 관심은 미진하였다고 볼 수 있 다. 이제까지 실시되어온 진단의 작업 또한, 거시구조 (제도)와 미시현상(경험) 중 하나의 축에 의존해온 경향 이 있었다. 반면, 양 축이 수렴(분산)되고 연결(단절)되 는 조정의 과정에서 제도의 '실제(Smith, 2005)'를 이해 하고, 그곳에 붙박인 '논리(Choi, 2009)'를 밝히려는 노 력은 희소하였다.

이를테면 국제 및 국외 스포츠코칭 기관들(e.g., Eramus Programme of the European Union, 2017; Sport and Recreation New Zealand, 2006; International Council for Coaching Excellence, 2013; National Association for Sports and Physical Education, 2006)은 자격제도의 근간 인 프레임워크(framework)2)의 논리를 바탕으로 교육과 정을 개발함으로써, 예비 코치들이 갖춰야할 전문성 (또는 역량)의 최소기준을 체계적으로 확립해왔다. 하 지만 국내의 경우 프레임워크 자체가 부재할뿐더러 (Han, Shin \& Lee, 2018, p. 248), 현행 자격제도 내 교육 과정이 어떠한 목적, 내용, 방법, 평가원리에 기초하여 구성된 것인지, 아울러 이를 통해 육성하고자 하는 체 육전문인의 모습이 무엇인지 다소 불분명한 실정이다 (Jung, 2020).

프레임워크가 전문인 양성을 위한 최소의 공통분모 를 구축하고, 이에 준해 그 이상을 추구할 이정표를 제 시한다는 점에서(Choi, 2015, pp. 1-12), 자격제도의 '진 단' 작업은 추후 코칭교육의 방향을 안내할 '표준(Jung, Lee \& Lee, 2019)' 도출을 위해 반드시 선결되어야 할 요

1) 전향(前向)은 앞을 내다보며 장차 교육에서 가르쳐야할 내용 과 방법을 '처방'하는 관점이다. 이와 반대로, 후향(後向)은 교 육이 특정내용을 모종의 방법으로 가르치는 행위라고 할 때, 어떠한 논리적 가정을 받아드릴 수밖에 없는지, 뒤로 물러나 '이해'하는 관점이다(Lee, 2000, p. 267; Ryu, 1998, pp. 3-6).

2) 프레임워크는 스포츠코칭 관련 기관에 제공되는 코치교육과 자격 프로그램의 설계 및 개선을 위한 고려사항들(국제 우수 사례와 연구자료 등)이 포함된 (최소)공통의 플랫폼을 의미한 다(ICCE, 2013). 
건이다. 이처럼 자격제도의 실제를 바탕으로 교육논리 를 분석하는 접근은 현 시스템에 내장되어있는 '문제의 식'을 드러내는데 기여할 수 있다(Choi, 2004; 2009; Lawson, 1984; Tinning, 1991; 2002).

예컨대 모종의 문제를 해결하기 위해서는 특정 현상 을 문제사태로 설정하는 과정이 우선된다(Schön, 1979, p. 150). 이때 '문제'와 '문제가 아닌 것'을 구분하는 일 은 다양한 이데올로기 중 특정 가치체계를 내포한 프레 임의 선별을 통해 이뤄진다(Tinning, 1991). 이와 같은 문제설정의 과정이 비가시적인 까닭에(Lawson, 1984), 우리는 종종 해결해야할 문제가 자연스레 주어진다는 착각에 빠진다(Schön, 1979). 하지만, 가시적인 문제해 결(problem solving)의 결과에 파묻혀 문제설정 (problem setting)의 과정을 도외시하는 경향아래에는 탈 전문화(de-professionalization)의 위험이 잠재되어있 다(Schön, 1979; 1983; 1987). 따라서 현 자격체제에 어 떠한 '문제의식'이 세팅(setting)되어있는지를 '진단'하 지 않고 해결책에 집중하는 경향은 경계되어야 한다. 체제의 근저에 흐르는 문제의식, 그것의 진단을 간과한 ‘처방'은 시스템의 근본적 한계를 쇄신하기보다, 표피 적 변화만을 되풀이할 수 있기 때문이다.

이러한 맥락에서 조정(Smith, 2005)의 개념은 미시현 상(micro)과 거시구조(macro)의 '접점(meso)'을 주시함 으로써(Campbell \& Gregor, 2002; DeVault, 2006; DeVault \& McCoy, 2006; Peacock, 2017; Walby, 2005), 자 격제도 내 교육과정의 현상과 구조를 진단하는데 유용 한 관점을 보충할 수 있다. 구체적으로 말하여, 조정 (coordination)은 숱한 텍스트로 짜인 제도적 배열이 개 인들의 행위를 특정방향으로 유도(macro)하거나, 이와 반대로, 불특정 개인들이 제도적 질서를 무시하고 기존 의 관행을 고수(micro)하는 불협(-타협)의 '프로세스'와 '메커니즘'을 이해하는데 적합한 렌즈(meso)를 제시할 수 있다.

이에 본 연구는 정부 및 산하기관의 제도적 텍스트와 연수생들의 경험적 언어가 상응-상충되는 '지점'을 탐 색하고 양 축이 조정되는 '궤적'을 추적하여, 자격제도 내 교육과정의 '실제'와 '논리'를 확인하고자 한다. 이 를 위해 설정한 구체적 연구문제는 다음과 같다. 첫째, 자격시스템과 연관된 제도적 텍스트와 경험적 언어는 어떻게 조정되는가? 둘째, 자격제도의 밑바탕에 깔린
교육논리의 특징 및 한계는 무엇인가? 전술된 연구문 제의 규명은 향후 자격제도 내 커리큘럼의 모태인 프레 임워크 개발에 유효한 함의를 제공할 것으로 기대된 다.

\section{연구방법}

연구자는 상술된 문제를 탐구하기 위해 제도적 문화 기술지(institutional ethnography)를 채택하였다(Smith, 2005). 이 방법론은 제도와 일상이 어떻게 조직되는지 를 이해하고, 누구나 소속되어있는 일(Work)의 실제를 밝히는데 중점을 두기 때문에, 교육, 복지, 의료와 같은 전문직 양성분야의 연구에 유용하다(p. 7).

\section{방법론의 관점}

본 연구가 참고한 제도적 문화기술지의 주요관점은 다음과 같다. 첫째, 개인과 제도는 능동적 주체이다. 고 로 양 축이 조정되는 과정에서 사회적 실제가 조직된 다. 둘째, 개인의 경험기반 언어와 기관의 제도기반 텍 스트는 조직화 작업의 핵심역할을 담당한다. 실제를 조 직하는 특수한 조정의 형태가 언어와 텍스트에 녹아있 기 때문이다. 셋째, 개인들의 공통경험에 집중하기보 다, 단절(disjunction)과 차이(difference)를 이어 맞추면 서 조정의 시퀀스를 추적한다. 넷째, 조정의 과정에서 개인의 일상이 제도의 배열과 어떻게 일치-불일치되는 지를 파악하며, 사회적 조직도(social organization map) 를 구체화한다. 다섯째, 조직된 실제에 기초하여 문제 틀(problematic)을 확장시켜나간다. 문제 틀은 연구방 향의 설정부터 제도와의 관계로 더 깊숙이 들어가는 계 속적 단계이다. 문제 틀의 참조를 통해 일상의 일들 (works)이 제도적 배열과 확장된 고리로 연결되어있음 을 이해하게 된다.

이와 같은 제도적 문화기술지의 관점은 조정의 과정 에 비추어 자격제도의 조직된 실제(organized reality)를 '구체적'으로 묘사하고, 그곳에 내장된 교육논리 (education logic)를 ‘구조적'으로 분석하는데 적격한 틀 을 제공할 것으로 사료된다. 


\section{연구 참여자}

연구자는 유목적 표집방법의 일환인 준거선정법을 활용하여(Patton, 2015), 평균 2.4년의 경력을 지닌 참여 자 7명을 모집하였다. 선별과정에 적용된 준거는 다음 과 같다. 첫째, 2015년 개편이후 시행된 2급3) 생활스포 츠지도사 자격취득자, 둘째, 체육전공 학위소지자, 셋 째, 현장근무 경력자였다. 참여자들의 배경정보는 다 음과 같다(Table 1).

Table 1. Characteristics of Research Participants

\begin{tabular}{ccccccc}
\hline \hline & Name & Gender & Sport & $\begin{array}{c}\text { Acquisition } \\
\text { year }\end{array}$ & $\begin{array}{c}\text { Academic } \\
\text { degree }\end{array}$ & $\begin{array}{c}\text { Training } \\
\text { institution }\end{array}$ \\
\hline 1 & Kim & Male & Taekwondo & 2018 & Bachelor & Seoul \\
\hline 2 & Park & Female & Gateball & 2017 & Bachelor & Gyeonggi \\
\hline 3 & Lee & Male & Basketball & 2016 & Bachelor & Gyeonggi \\
\hline 4 & Cho & Male & Wrestling & 2019 & Bachelor & Seoul \\
\hline 5 & Se0 & Male & Bodybuilding & 2018 & Bachelor & Gyeonggi \\
\hline 6 & Ma & Male & Bodybuilding & 2017 & Bachelor & Gyeonggi \\
\hline 7 & Lim & Female & Bodybuilding & 2018 & Bachelor & Gyeonggi \\
\hline \hline
\end{tabular}

\section{자료수집 및 분석}

연구자료는 2020년 08월부터 12월까지 현지자료와 반 구조화된 면담을 통해 수집되었다. 면담은 코로나 감염위험을 최소화하기 위해 화상회의 프로그램 (Zoom)를 사용하였고, 참여자의 일정에 맞추어 2 3회, 40 50분 내외로 진행되었다. 인터뷰 3일 전 내담자에 게 가이드라인을 제공함으로써, 참여자들이 연구주제 와 질문의 맥락을 이해할 시간을 확보하였다. 활용된 가이드라인은 '검정영역' 질문(필기 및 구술·실기의 준 비과정, 검정절차 및 환경, 운영방식, 관리감독체제, 문 항 및 질의내용에 관한 인식, 검정전후의 변화 등)과 '교 육영역' 질문(연수 및 실습의 전개과정, 영역별 목표의 인지, 내용구성·운영방법·평가체계에 관한 인식, 참여

3) 본고에서 ' 2 급'을 연구의 초점으로 설정한 이유는 첫째, 해당 급수가 생활스포츠지도자로서의 공식자격을 부여하는 최소요 건이기 때문이다. 둘째, 국민체육공단의 자격취득 통계자료 (2019)를 참고할 때, 1 급 자격(258명)에 비해, 2 급 자격 $(10,177$ 명)이 보다 높은 대표성(약 $97.5 \%)$ 을 함의한다고 판 단하였기 때문이다.
정도, 학습 분위기 및 풍토, 역할, 현장 실효성, 교육전 후의 변화 등)으로 구성되었다. 현지자료는 SNS 및 우 편을 통해 참여자자료(필기노트, 연수교재, 시간표 등) 와 기관자료(보고서, 보도문, 안내문 등)가 수집되었다.

취합된 자료원은 '모으기(assembling)'와 '그리기 (mapping)' 방법으로 분석되었다(Smith, 2005). (1)경험 기반 언어 간 차이(Nichols \& Griffith, 2009), (2)텍스트기 반 언어 간 차이(Daniel, 2004), (3)경험기반 언어와 텍스 트기반 언어 간 차이를 모은 뒤, 비교, 대조, 나열하며 조직화의 토대를 구축하였다. 개인과 제도, 어느 한 축 에 매몰되지 않기 위해(McCoy, 2006), 차이들의 연결, 단절, 관계, 시퀀스, 조정양상을 그리면서 제도의 '실 제'에 다가가고자 하였다(Kim, 2013). 이러한 절차를 거 쳐 각각의 텍스트들이 어떻게 제도적 배열을 조직하는 지, 제도적 세팅 위 개인들의 경험이 어떻게 구성되는 지, 나아가 기관의 텍스트와 개인의 경험이 어떠한 과 정으로 조정되는지를 '주의 깊게 추적(careful tracing)' 하였다(Talbot, 2017, p. 17). 이후 조직된 실제에 입각하 여 자격제도의 교육논리를 구체화하였다.

\section{진실성 및 윤리성}

연구자는 진실성의 향상을 위해 참여자확인, 자료검 증, 비판적 동료검토를 실시하였다(Patton, 2015). 참여 자와 자료를 공유한 뒤, 본래 의미와 일치하는지 확인 하였다. 불명확한 부분은 참여자확인 및 추가면담을 통 해 파악한 후 괄호에 삽입하였다. 추가질문의 내용이 간소한 경우, 참여자의 편의를 고려하여 SNS를 통해 간 단한 문답을 주고받았다. '자료 내', '자료 간' 국면에서 상충의 지점이 발견될 시 전후 문맥을 재확인하였다. 동일전공 박사학위자 2 명과 방법 및 결과에 관한 협의 를 실행하였다. 참여자의 개인정보를 익명화하고 모자 이크 처리함으로써 신원노출의 위험을 경계하였다.

\section{결과 및 논의}

연구결과는 자격제도의 '조직된 실제(1절)'와 '교육 논리(2절)'를 중심으로 제시된다. 각 절의 도입부에 '사 회적 조직도'와 ‘확장된 문제 틀'의 도식을 제시한다. 


\section{1. 조직된 실제: 개인과 제도의 조정과정}

개인과 제도가 서로를 조정하며 사회적 실제를 조직 하듯이(Smith, 2005), 참여자들은 필기, 구술·실기, 연 수, 실습영역에서 조정(일치·불일치)을 거치며, 자격시 스템을 향한 의문, 불만, 수긍, 타협의 (자기)합리화 과 정을 겪고 있었다.

\section{1) 필기검정}

문체부는 필기검정의 개편을 위해 문제유형, 난이 도, 매뉴얼 및 지침 등을 개발했다(MCST, 2014, p. 12). 이러한 개편의 취지와 같이, 일부 참여자들은 문항의 난이도 설정에 긍정적이었다. 그러나 종목 및 직무와 괴리된 문항출제가 지속되기도 했다. 참여자들은 이러 한 불일치 현상을 마주한 후, 필기검정을 무용한 벼락 치기 과정으로 인식하였다(Table 2).

Table 2. The social organization map of written test

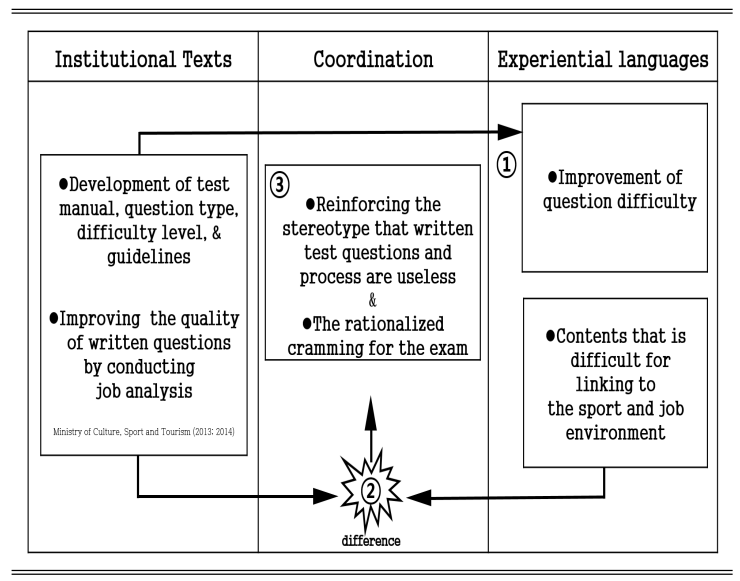

(1) 일치: 문항의 난이도 개선

일부 참여자는 공부하면 누구나 도전할(통과할) 수 있을 정도로 문항의 난이도가 설정된 점에 만족하였다.

책보고 공부하고 외우면 접근할 수 있는 난이도라서 조건에 맞게 누 구나 도전을 할 수 있다는 점이 아주 좋았습니다(서코치).

유사한 맥락에서 $\operatorname{Kim} \& \operatorname{Kim}(2017$, p. 263)은 스포츠 교육학 과목의 난이도에 관한 385명의 인식을 조사한 결과, 양극단의 비율(매우 어렵다 $-5.2 \%$ 와 어렵지 않았
다-8.1\%)이 가장 낮게 응답되었음을 보고했다. 이러한 자료와 진술은 현행 필기검정이 난이도 부문에서 개편 의도와 부합하고 있음을 대변한다.

하지만, 난이도 개선에 따른 '개방성(Jung, Lee \& Lee, 2019, p. 154)'의 상향은 전문성의 하향을 초래하는 양 날의 검이기도 했다.

긍정적이지만 또 부정적일 수 있는 게 자격증의 메리트가 떨어진다 고봐요 $(\cdots)$ 누군가를 지도하는 지도사자격이라는 면에서 난이도 를 더 높게 하면 보다 퀄리티 있는 자격증이 될 수 있을 거라 생각합 니다(서코치).

(2) 불일치: 신청종목 및 직무현장과 연계되지 않는 내용 문체부는 직무분석(체육지도자 심층인터뷰 및 실태 조사)을 통한 필기검정의 질적 제고를 도모했다(MCST, 2014, p. 12). 하지만, 일선의 장면에선 여전히 신청종목 및 직무현장과 동떨어진 문항이 출제되고 있었다.

Table 3. Written test questions in qualification system

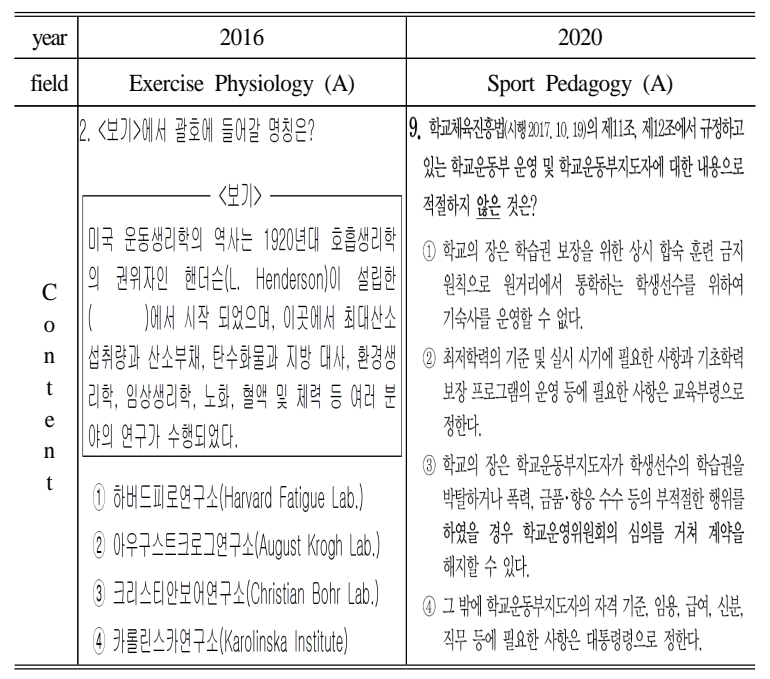

〈Table 3〉의 2016년 운동생리학 문항(좌)이 특정학자 가 설립한 연구소의 명칭을 묻는다면, 2020년 스포츠교 육학 문항(우)은 생활스포츠지도자 자격 응시자들에게 학교운동부 관련 법령을 질의한다. 참여자들은 이와 같 은 단순사실 위주의 정보(좌)와 타당성이 미흡한 문항 (우)으로부터 어떻게 '신청종목과의 연관성' 및 '직무현 장에서의 실효성'을 모색할 수 있는지 의심하였다. 
이걸 왜 하고 있는지 의문이 드는 것 같아요. 그냥 문제풀이로만 공 부만 하고 있으니까. 이렇게 공부를 해서 가면 실제 지도현장에서 자기지식으로 전달할 수 있을까? (이코치)

(현장) 적용이 아예 안 될 것 같습니다. 일단 전공자 입장에서도 잘 모르는 것인데 생활스포츠 참여하시는 분들이 이런 정보를 알고 싶 어 할까요? (조코치)

이상의 실례와 진술은 개편이후의 필기검정 또한 암 기수준의 정보, 용어정의 관련 문제, 문항의 타당성 부 족 등(Kim \& Kim, 2017; Han, Shin \& Lee, 2018), 비실제적 내용체계로 배포되어왔음을 증빙한다.

(3) 조정: 무용한 과정으로의 고착 및 합리화된 벼락치기 참여자들은 필기검정이 스포츠코치로서 갖춰야할 지식의 최소단위(Kim\& Kim, 2017)를 공급하기보다, 무 기력한 관념(Whitehead, 1929)을 제공한다고 인식하였 다.

내가 볼 때 1000 명중에 999 명은 기대 안 해요. 벼락치기해서 공부 하고 나면 훅 날아가 버려요(김코치).

솔직히 어차피 시험끝나면닦ㄲ먹을 것같아서눈에 익도록만봐아겠 다. 커트라인만 넘기려는 게 있어서, 처음부터 사람들도 준비기간을 되 게짧게 봅니다. $(\cdots)$ 1주일 정도요(조코치).

이들은 필기검정을 "벼락치기" 그 이상도 이하도 아 닌 것으로 수용하며, 짧은 시간 내 “커트라인만 넘기”면 된다고 타협하였다.4) 나아가 이러한 반응은 필기검정 으로 예비 코치의 이론적 자질을 검증하기 어려운 까닭 에, 18 세 이상 누구나 지원할 수 있도록 요건을 완화한 조처(MCST, 2014)가 자격의 위상을 실추시킨다는 비판 (Cho, 2016; 2020)으로 이어지기도 했다.

체육종사자라면 꼭 숙지하고 있어야 하는 이론이 있다고 생각하는 데 현재 필기시험에서는 이런 과목들을 선택하지 않고도 합격할 수

4) 이러한 타협의 입장은 제도적 텍스트(KMGL, 2019.12.10; MCST, 2013.07.01; 2014; 2015a)에서도 확인된다. 필기검 정의 내용체계를 '아는 것'과 신청종목을 ‘하는 것'이 성질상 구분됨에도 불구하고, 현행제도는 국가대표 및 프로스포츠 경 력만으로 면제를 부여한다. 이러한 면제조항은 문항을 기획. 유통하는 정부와 문체부조차 필기검정을 필수적인 검증절차 가 아닌 부수적인 의례절차로 가정하고 있음을 반증한다.
있고5) 그래서 비체육과 전공 지도자의 자격증 취득 전과 후를 비교 해봤을 때 전문성 면에서 큰 차이를 보이지 않을 것 같고 $(\cdots)$ 안그 래도 우리나라에서 체육종사자들은 몸만 쓸 줄 안다는 인식이 강한 데, 이렇게 현장에서 쓰이지도 않고, 시험만을 위한 문제를 출제한 다면 생활스포츠지도자들을 무분별하게 배출할 거고 부정적 인식 은 더욱 강화될 것이라고 생각합니다(조코치).

상술된 사례들은 현행 필기검정이 '비실제적 내용체 계'를 유포하고, '모순적 텍스트(면제 및 축소조항)'를 배치함으로써, 응시생들이 필기검정을 무익한 과정으 로 여기도록 종용해왔음을 방증한다.

\section{2) 구술 · 실기검정}

문체부는 구술·실기검정의 개편을 위해 평가방법, 심 사모듈, 기본문항 - 답안을 개발했다(MCST, 2013.07.01; 2014). 이러한 텍스트와 같이, 일부 참여자는 종목 및 직 무와 연관된 질의·응답이 전개된 점에 만족하였다. 그러 나 대다수는 형평성이 미흡한 검정절차 및 환경을 경험 한 후, 편법에 동참하고 시스템에 불신을 품었다(Table 4).

Table 4. The social organization map of oral \& skill test

\begin{tabular}{|c|c|c|}
\hline Institutional Texts & Coordination & Experiential languages \\
\hline 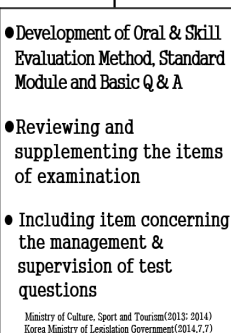 & $\begin{array}{l}\text { (3) (Self)-Rationalization } \\
\text { of undesirable ways } \\
\text { and Distrust for } \\
\text { certification }\end{array}$ & $\begin{array}{l}\text { - Improvement for } \\
\text { Contents system } \\
\text { linked to } \\
\text { registered sport } \\
\& \text { job context }\end{array}$ \\
\hline & difference & \\
\hline
\end{tabular}

5) 문체부는 개편 전 "필기시험 과목이 많아 부담이 컸던 문제 (MCST, 2013.07.01, p. 4)"를 해소하고자 7과목 중 5과목 을 선택하는 방식으로 범위를 축소했다(MCST, 2014, p. 5). 그러나 이러한 축소조항은 필기검정의 특정(혹은 모든) 내용 체계가 예비 스포츠지도자의 이론적 자질함양에 반드시 필요 치 않다는 기조를 대신한다. 예컨대 스포츠를 '가르치는 일' 에 종사하는 생활스포츠'지도자'들이 스포츠'교육'의 지식을 습득(선택)하지 않아도 무방하다는 것이다. 
(1) 일치: 신청종목 및 직무현장과 연계된 내용체계 참여자들은 구술검정의 내용체계가 신청종목 및 직무 현장에서 활용도가 높기 때문에 유익하다고 발언하였다.

구술이더 기억이 나는데, 현장에 더 가까운 내용이어서에요. 종목특 성에 대해서 나오는 게 많아서 더 기억에 많이 남았던 것 같습니다. 필기시험은 단순히 학문적인 것에 집중되어있지만, 구술시험은 보디 빌딩에 더 중점적으로 되어있기 때문에 더 와 닿았습니다(서코치).

현장에서쓸 수 있는 것들이라서 기억에 잘 남았던 것 같아요. 의식 없는 환자, 응급상황에서의 대처법들이 활용될 수 있고 도움이 된다 고 느겨서 재밌게 공부했어요(마코치).

전술된 반응에 기초할 때, 구술검정의 내용체계는 신청종목 및 직무현장의 맥락과 흡사하게 구성되었고, 이로 인해 예비 생활스포츠지도자들이 향후 유사상황 에서 해당지식을 활용할 가능성(Schön, 1983)을 얼마간 확보한 것으로 이해된다.

\section{(2) 불일치: 시험환경 및 절차의 형평성 부족}

공정성 강화의 텍스트는 시험기준, 관리 및 감독사 항을 규율했지만(KMGL, 2014.07.07; MCST, 2014), 참여 자들은 '공간'과 '시간'의 국면에서 형평성이 결여된 시 험을 경험하고 있었다.

오픈된 장소에서 실시되어서 (이)전 사람이 실기시험 하는 것을 볼 수가 있었어요. 그 문제가 계속 반복돼서 출제되어가지고, 뒷사람 들은 시험문제가 뭔지 알고 주구장창 연습하는 그런... 똑같은 문제 만 계속 출제되었습니다(조코치).

조코치는 시험장소의 '개방'으로 문제가 노출되었음 에도 불구하고, “똑같은" 문제가 반복 출제되는 한계를 거론했다. 뒷 순번에 배치된 응시생이 앞의 시험과정을 참고하여, 특정 문제만 “주구장창” 준비하면 합격은 따 놓은 당상이라는 것이었다.

더불어 시험시간의 '연장'에 따른 문제도 확인되었 다. 연수생들은 오전 혹은 전일 온라인 카페에 공유된 출제문제를 파악하고, 수렴된 문항과 답안에 집중함으 로써, 보다 유리하게 검정과정을 공략할 수 있었다.

후기를 찾으면서 카페를 봤는데 어떤 곳은 오전시험 문제가 오후에그
대로 나온다고 해요. 이건 형평성을 위해서 개선되어야 한다고 생각합 니다. 오전시험보신 분들이시험에 뭐가나왔다하면 오후사람들은그 걸 보고 들어가면 그게 나오는 거에요. 또 (실기·구술) 시험을 2일 동안 보는데, 전날 문제랑 다음날 문제랑 똑같았다는 후기가 많았고요 (시 험을) 미리 보는 사람은 피해 받는다고 느낄 수 있어요(마코치).

\begin{tabular}{|c|c|c|}
\hline 10.10 10:30 념자 후기빈다 [2] & 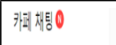 & \\
\hline - "월 일 10시반 어자 & & 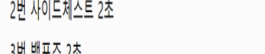 \\
\hline 10人130분 - & \multirow{6}{*}{  } & \\
\hline 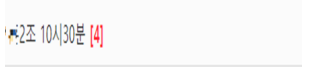 & & 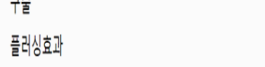 \\
\hline 일 9:30=" 여자 [16] & &  \\
\hline 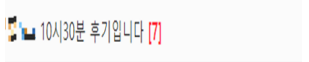 & & 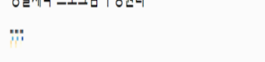 \\
\hline 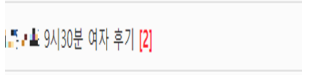 & & : \\
\hline 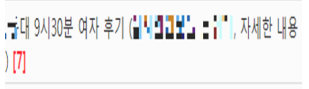 & & 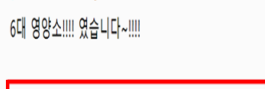 \\
\hline 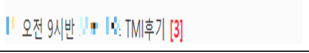 & 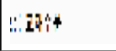 &  \\
\hline
\end{tabular}

Fig 1. Test information in the blog which Ma coach mentioned

특정 온라인사이트에는 시험지역, 장소, 시간정보 가 열거되어있고(좌), 상세한 시험내용(우)이 공유되고 있었다. 특히 우측 하단의 사각 테두리를 주시하면, “똑같은” 문제가 출제되는 징후를 포착할 수 있는데, 이러한 정황들은 구술·실기검정의 공정성 보완이 필 요함(Ahn, Kim \& Kim, 2016, p. 471)을 시사한다.

(3) 조정: 편법의 합리화 및 자격의 불신

일부 참여자들은 지인들의 소식과 온라인 매체를 통 해 검정의 한계를 익히 들어온 까닭에, 별다른 죄책감 없이 편법에 동조하게 된다고 고백하였다.

같이 준비했던 친구들도 그랬고요. 저 같은 경우도 오후 첫 번째 조 였거든요. 점심시간에 뭐 나왔나 찾아보고 그랬어요(마코치).

형평성의 문제가 있을 수 있지만, 저는 거의 모든, 대부분의 사람들 이 (온라인 사이트를) 알고 있다고 생각해서...(임코치).

이들이 위의 전략이 구술·실기검정의 절차적 공정성 을 훼손하는 행위임을 주지하면서도, 편법에 가담한 연 유는 이미 그것이 통과의 미명하에 자행되는 공공연한 
관행으로 합리화되었기 때문이었다. 물론 이상의 현상 은 운영기관의 '관리·감독 부실' 및 '문제 풀(pool) 빈약' 으로부터 파생된 것이었지만, 이를 이용하는 편법의 일 반화는 향후 자격시스템의 불신을 조장하기도 했다.

진짜 이건 아무나 따는 자격증이구나. (생활스포츠지도자의) 전문 성을 보장하지 않는 자격증이구나, 이게(자격증) 전문성을 나타낸 다고 생각하지 않아요. 그런데 일반인들은 이런 평가과정을 모르니 까 자격증 자체만 믿는 거고요(조코치).

\section{3) 일반연수}

문체부는 연수의 개편을 위해 프로그램, 교수법, 표 준교재 등을 개발하였지만(MCST, 2013.07.01; 2014), 연 수현장에서는 개편이전의 한계가 되풀이 되고 있었다. 참여자들은 이러한 현상을 마주한 뒤, 연수의 내용과 방 식에 거부감을 갖고 임의목적을 추구하였다(Table 5).

Table 5. The social organization map of lecture

\begin{tabular}{|c|c|c|}
\hline Institutional Texts & Coordination & Experiential languages \\
\hline $\begin{array}{c}\text {-Anyone over } 18 \text { can } \\
\text { apply qualification to } \\
\text { lower the entry barrier } \\
\text { by abolishing }\end{array}$ & \multirow{3}{*}{$\begin{array}{l}4 \text { (4) } \\
\text { •(Self)-Rationalization } \\
\text { by pursuing } \\
\text { arbitrary purposes }\end{array}$} & \multirow{2}{*}{$\begin{array}{c}\text {-Repeating the limits } \\
\text { of university } \\
\text { education focusing } \\
\text { on academic theory }\end{array}$} \\
\hline 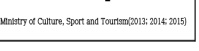 & & \\
\hline 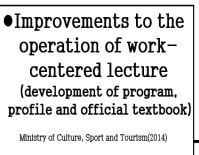 & & $\begin{array}{l}\text {-General and Basic } \\
\text { theory not linked to } \\
\text { the sport, job and } \\
\text { certificate type }\end{array}$ \\
\hline 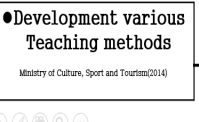 & 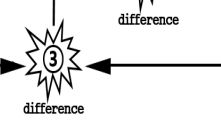 & $\begin{array}{l}\text {-The prevalence of one } \\
\text { way teaching methods }\end{array}$ \\
\hline
\end{tabular}

(1) 불일치: 학문중심 대학교육의 한계 답습

문체부는 대학교육으로 취득한 "학력이 체육지도자 의 업무수행에 본질적인 내용이라 할 수 없기" 때문에 (MCST, 2013.07.01, p. 2), "18세 이상이면 누구나 응시" 할 수 있도록 진입장벽을 낮추었다(p. 3). 하지만, 역설 적이게도, 운영기관의 연수는 학문위주 대학교육의 한 계(Choi, 2009)를 해소하기보다, 되레 그것을 답습하는 행보를 보이고 있었다.

너무 짜증났어요. 체육대학 나왔던 사람들은 기본적으로 다 들었고
알고 있는 내용인데 하루 8시간씩 앉혀놓고 계속 연수만 듣게 하는 데 이게 어떤 교육효과가 있는지 모르겠어요(이코치).

이미 저희는 대학이란 교육시설에서 학비를 내고 배웠는데, 더 일반 적인 연수를 또 듣게 되잖아요. 이걸 조금 더 차별화를 두면, 학위를 얻은 사람들이 대학에서 배우지 못한 것을 자격과정에서 배울 수 있 는 기회를 얻는 거잖아요. 근데 너무 성의 없는 강의가 계속돼요. 주 제, 내용도 필기랑 비슷한데, 진행방식도 흥미롭거나 유익함이 없 어요(임코치).

연수내용이 체육대학의 학문중심 교육과정과 중복 되는 까닭에, 참여자들은 불필요한 시간 및 경제자원의 소모를 경험하며(Kwon, 2017), 이중고(Oh, 2000)를 호 소했다. 이어서 임코치는 내용의 깊이가 얕고 기간이 짧은 연수만으로 이론적 기반의 확보가 어렵기에, 비 체육계열 전공자의 진출 수가 증가할수록 지도자를 향 한 소비자의 신뢰가 추락하는 결과를 당면할 것이라 첨 언했다.

대학교육에서도 이론교육이 많긴 하지만, 이렇게 더 얕고 단기간에 취득한 자격증으로 현장에 나가는 인원이 많아지면 스포츠현장의 질이 떨어질 것은 당연하고, 질적인 만족을 하지 못한 소비자들의 기대 또는 신뢰감 역시 자연스럽게 감소할 거라 생각해요(임코치).

물론 문체부의 저의는 학력의 진입장벽에 따른 차별 을 해소하기 위함이었지만(MCST, 2013.07. 01), 실상 그 것은 "(고등)체육계열 교육과정의 전문화를 무시(Cho, 2016, p. 167)"하고 “학사소지의 의미를 말살(p. 172)"시 킴으로써 자격의 탈 전문화를 촉진한다는 것이었다.

(2) 불일치: 실제와 괴리된 원론위주의 내용체계 문체부는 자격유형별 전문화와 직무역량의 증진을 위 한 실무연수로의 개편을 공표해왔으나(MCST, 2013.07.01; 2014), 일선에선 신청종목의 특수성, 자격유형의 독특성, 직무현장의 연관성을 고려치 않은 원론위주의 연수가 지 속되고 있었다.

공통적으로 이루어지는 연수다보니 적용하기 어렵죠. 제가 개인적 으로 따로 질문을 드려도 답변을 주시지 못했어요(박코치).

아우를 수 있게 이론수업을 하다보면 뜬구름 잡기식이 되다보니까 재미없어지고, 또 다 안 듣게 돼요(마코치). 
참여자들은 원론적인 내용으로 전체의 맥락을 포섭 하다보니 종목, 실무, 자격과 동떨어진 "뜬구름 잡기 식” 연수가 되어버린다는 점에 회의적이었다. 이러한 반응은 현 자격체제가 지도대상에 따른 유형별 전문화 를 기획하였지만(MCST, 2014), 자격유형의 구별 없이 획일적인 내용을 보급해왔다는 분석(Jung, 2019; Kang, 2018; Park \& Park, 2014)을 뒷받침한다. 일례로 참여자 들이 사용한 〈2급 생활스포츠지도사 연수교재〉(Korea Sport Promotion Foundation: KSPF, 2017)의 스포츠윤리 단원(pp. 26-48)을 살펴보면, 대부분의 내용(Content)이 전문스포츠 중심(학교운동부, 프로, 국가대표)으로 편 중되어있음을 확인할 수 있다(Table 6).

Table 6. Lim coach's book (KSPF, 2017, p. 54, 70)

\begin{tabular}{|c|c|}
\hline Content & Activity \\
\hline 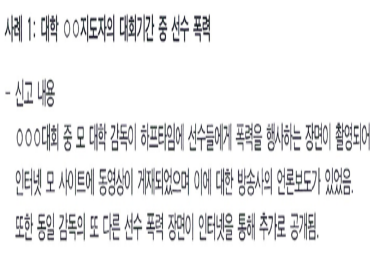 & 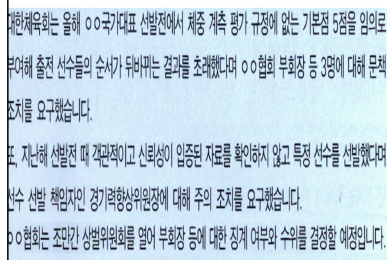 \\
\hline  & 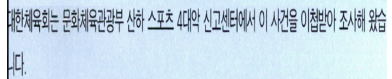 \\
\hline 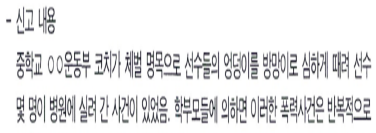 & 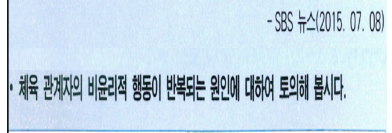 \\
\hline 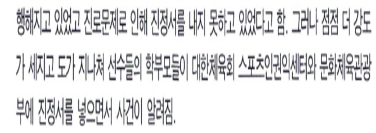 & \\
\hline
\end{tabular}

위의 사례를 참고할 때, 예비 생활스포츠지도자들은 연수과정에서 원론(혹은 전문체육)중심의 내용을 생활체 육의 맥락으로 전환하거나, 앞선 마코치의 진술처럼, 연 관성이 부족한 “뜬구름 잡는” 소리로 치부할 공산이 컸다.

(3) 불일치: 일방통행식 강의의 만연

제도적 텍스트는 다양한 교수기법의 개발과 활용을 요청해왔지만(KSPF, 2017; MCST, 2014), 일선의 강사들 은 제도의 요구를 외면한 채, 일방통행의 “정보전달”을 고수하고 있었다.

연수는 정보 전달로만 진행이 되었고요. 저희가 직접 참여하는 것이
없어서 많이 지루했어요. $(\cdots)$ 강의자분이 그냥 하고 싶은 말을 오 셔서 한 것 같은 느낌이 들었어요. 8시간씩 앉아서 수업을 계속 듣 기만 하니 대부분 많이 자요(마코치).

일단 학습자이기 때문에 강의를 듣는 입장이고, 강사님 말씀하시는 거에 귀를 기울여야하는 것 말고는 역할이라는 게 딱히 없었습니다 (서코치).

참여자들은 오랜 시간 자리에 앉아 연수를 경청할 뿐인 역할수행을 버거워했다. 강사가 “그냥 하고 싶은 말”을 하고 간 것처럼, 학습자의 반응, 참여, 소통을 고 려치 않은 정보주입을 겪으며 졸음에 빠졌다. 그나마 고무적인 것은 공식교재 내부에 학습자들이 연수에서 배운 내용을 유사상황에 대입하고, 그룹별로 토의해볼 수 있는 활동영역(Activity)이 마련되어있다는 점이다 (Table 6). 하지만, 참여자들은 상술된 활동영역과 무 관하게 일방통행의 강의를 들어야 했고, 표준교재와 동떨어진 내용을 학습하며 집중력을 잃어갔다.

강사님이 준비해오신 ppt랑 교재랑 내용이 천차만별이고 교재를 나눠준 의미가 없을 정도로, 강사님 별로 준비해오신 ppt로 진행하 기 때문에 듣는데 어려움이 있었습니다(임코치)

유사한 맥락에서 $\operatorname{Kim}(2020$, p. 121)은 이론강사 개인 이 “준비해온 자료”로 연수를 진행하는 것이 편리하기 때문에, 표준교재를 사용하지 않는 사례를 공유한 바 있 다. 물론 문체부는 "개별 연수기관의 특성을 반영하여 교과과정(을) 운영”할 수 있도록 명시하고 있지만(MCST, 2014, p. 13), 이처럼 개별 강사수준에서 자의적으로 편 성한 내용을 공급할 경우, 실천지향의 구조(Table ()6)를 포함한 표준교재의 존재이유를 묵살하고, 일방통행의 주입식 연수문화를 강화할 위험이 있다.

(4) 조정: 임의목적 추구를 통한 합리화

참여자들은 앞선 불일치 현상을 직면한 뒤, 연수의 내용을 신청종목 및 직무현장과 하등 관계없는 것으로 취급하며 임의목적(“시간 때우기”)을 추구하였다.

6) 이외에도 국민체육진흥공단은 표준교재에 “작성, 실행, 적용, 설명, 설계, 실시할 수 있다”와 같은 실천지향의 '교과목표'와 문제해결 시나리오, 사례연구, 그룹별 토론 등의 다각적 '평 가유형 및 방법'을 포함하고 있다(KSPF, 2017, p. 16, 18). 
연수는 시간 때우기로 어쩔 수 없이 들어야하니까. 다 앉아있는 것 같아요. 시간만 채우자 이런 생각만 하게 돼요(마코치).

제가 강사면, 연수생들이 멍 때리고 듣는 모습을 보면서 “내가 이걸 왜 해야 하지? 그냥 나도 시간 때우고 가아겠다" 이런 생각이 들것 같은 거에요(웃음) $(\cdots)$ 앉아서 핸드폰 보다가 강사분이 이론으로 들어가면 "아또 시작이다 이거 알아도 소용도 없는데, 그냥 화장실 이나 가아겠다" 이건 시간 때우는 용이기 때문에 귀를 닫는 것 같습 니다(서코치).

이들은 연수의 내용을 알아도 소용없는 것으로 단정 하고 귀를 닫았다. 화장실가기, 휴대폰보기 등의 상규 적 행위로 시간을 때우면서 일방통행의 연수가 종료되 기만을 기다렸다. 유사한 맥락에서 $\operatorname{Kang}(2018$, p. 173) 또한 1 급 전문스포츠지도사 자격연수생들이 강 의 도중 개인 업무를 처리하면서, 오히려 시간을 아낀 다고 인식하는 문제를 제기한 바 있다. 이러한 정황들 은 자격유형 및 급수와 관계없이, 강의자가 학습자의 참여를 고려치 않고, 연수생 또한 이를 구실삼아 스스 로의 일탈을 합리화해온 연수현장의 풍토를 예증한다.

\section{4) 현장실습}

문체부는 실무역량을 갖춘 지도자 배출을 위해 현장 실습을 시행했다(MCST, 2014; 2015b). 그러나 일선의 실 습은 신설목적이 무색할 정도로 방만하게 운영되었다. 참여자들은 불일치 현상을 대면한 후 참여동기를 상실 하고, 실습을 형식적인 의례절차로 취급하였다(Table 7).

Table 7. The social organization map of field work

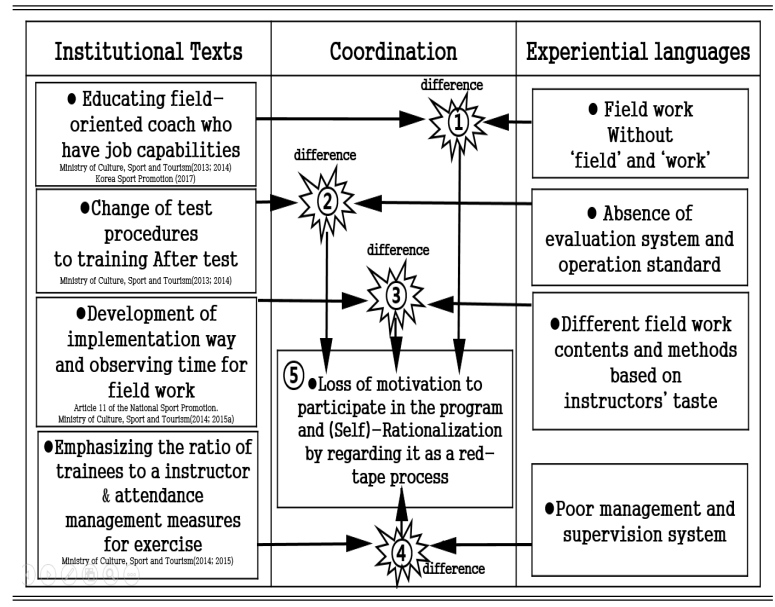

(1) 불일치: 현장과 실무가 생략된 현장실습

현장실습은 지도보조(9시간) 지도주관(14시간), 보 고서작성 및 제출(1시간)의 절차로 진행된다(KSPF, 2017, p. 13). 이러한 구성은 현장파견을 통한 직무역량 의 강화를 겨냥한 것이었지만(KSPF, 2017; MCST, 2014), 아이러니하게도 일선의 현장실습은 '현장'과 '실무'가 생략된 채로 진행되고 있었다.

저처럼 그냥 강의실에서 실습을 받는 게 보디빌딩(신청종목)과 과 연 얼마나 연관이 있을까 싶어요. 그 학교에 웨이트 장이 있는데, 많 은 인원이 학습하다보니까 웨이트 장은 가보지도 못했거든요. 그냥 일반이론 수업처럼 들었어요(임코치).

대학에서 종목이 없으니까 비슷한 종목에 가서 현장실습을 받도록 묶어줬어요. 그런데 저는 굳이 다른 종목에 갈 필요가 있나 싶었죠.

$(\cdots)$ 타 종목에서 실습을 받는다는 게 아무리 연관성이 있다고 해 도 도움이 되지 않을 것 같습니다(조코치).

참여자들은 현장실습이 일반연수와 다름없이 강의 실에서 전개되거나, 타 종목현장에서 진행되는 형편에 불만스러워했다. 물론 운영기관이 연수생의 신청종목 을 다루지 않을 시, 해당종목을 취급하는 유관센터로 이동할 수 있도록 협업체계를 구축해야 하지만(MCST, 2014, p. 18), 대학기관에서 유관센터로의 이동을 허가 치 않아, 특정인원들은 종목 및 직무현장과 괴리된 장 소에서 실습을 경험할 수밖에 없었다.

원래 현장실습이 다른 기관에서 진행하는 게 인정이 된다고 알고 있 었는데, 00 대 쪽에서는 그걸 악용하는 사람들이 있다고 해서 인정 해주지 않는다. 무조건 우리 걸로 들어라 그러시는 거예요. 굳이 현 장에서 쓰이지도 않는 것을 와서 들으라고 하는 것도 불만이었고, 왜 00대만 인정을 안 해주는 것에 대해서도 사람들이 불만이 굉장 히 많았어요(마코치).

또한, 이들은 '실무'와 연관되기 어려운 동작위주의 실습에 당혹스러워했다.

실습이 아니라 강사님들이 알고 있는 동작을 한 동작 한 동작을 따 라 했어요. 어떤강사님은 저희가 대부분 보디빌딩이었는데 골프 활 동을 하고, 이렇게 상황과 종목에 맞지 않는(마코치).

실습은 파트별로 했어요. $(\cdots)$ 학교에서 배웠던 실기가 더 많아가 지고 (돈이) 아끼웠죠. 배웠던 건데, 다 아는 건데(서코치). 
국민체육진흥공단은 현장실습의 편성내용을 실무 활동(회원관리 및 응대, 시설·용품관리, 프로그램지도, 응급대처, 컨디셔닝, 회원상담 등)으로 규정한다(KSPF, 2017, pp. 409-410). 하지만, 참여자들은 전술된 편성내 용과 연관성이 희박한 (타)종목의 실기동작을 배우면 서 의아했고, 20만원의 비용(MCST, 2015a, p. 8)을 아까 워했다. 이와 같은 사례의 누적은 특정 실습기관의 운 영방식이 현장과 실무를 체험해야 할 예비 생활스포츠 지도자들의 교육기회를 박탈할 수 있음을 시사한다.

(2),(3) 불일치: 평가체계의 부재 및 운영기준의 미비 문체부는 자격제도 내 교육과정이 필기검정을 준비 하기 위한 절차로 수렴되는 한계를 해소하고자(MCST, 2013.07.01), '교육 후 시험'에서 '시험 후 교육'으로 절 차를 변경했다(MCST, 2014). 하지만 이러한 절차개편은 평가체제가 부재한 환경7)을 조성하였고, 이는 연수자 들의 ‘태도문제’로 귀결되었다.

분위기가 사람들이 다 "아 이거를 들어야 일단 자격증이 나오니까. (필기, 구술·실기검정을) 다 합격했는데, 연수랑 이걸(실습) 끝내야 자격증이 나오기 때문에 어떨 수 없이 들어서 “아..." 이렇게 멍 때 리는 시간이 되게 많아져요(서코치).

서코치는 검정을 통과한 상태에서 실습을 이수해야 자 격이 발급되는 까닭에, 실습장에는 배워야겠다는 열의보 다, "어쩔 수 없이” 임하는 수동태적 분위기가 팽배하다고 술회하였다. 또한, 운영기준의 미비는 개별강사들이 "중 구난방식” 실습을 진행하거나, 시간단축을 빌미로 연수생 들과 수업분위기를 협상하는 사태를 용인하기도 했다.

강사 분들의 상황에 맞춰서 현장실습이 진행이 되어서, 참여하는 연 수자들에게는 흥미가 많이 떨어졌어요. 그런데 주변에도 들어보면 중구난방식으로 나는 골프였다. 나는 이거 배웠다. 나는 딴 거 배웠 다. 이런 말이 많았어요(마코치).

아무래도 연수자들이 다 흥미가 떨어져서 재미없어하니까, 최대한 빨리 끝내드린다고 1, 2시간만 집중해서 빠짝 하면 4시간으로 끊어 준다 이런(마코치).

7) 물론 현장실습 보고서양식(KSPF, 2017, pp. 415-417)은 '소 감 및 평가항목'을 포함한다. 그러나 실상 연수자 개인의 소감 작성과 제출여부만을 형식적으로 확인한다는 점에서(MCST, 2015a), 현장실습의 실질적 평가체제는 부재한 상태이다.
마코치는 현장실습의 '시행방안'과 '시간준수'를 명 시하는 텍스트(MCST, 2014; 2015a)와 달리, 강사들의 사 정을 맞추는데 급급한 실습기관의 운영방식을 미심쩍 어했다. 이어서 그는 동종업계 지인들의 소식을 통해 실 습을 향한 반감이 혼자만의 정서가 아님을 확인했는데, 이러한 진술은 연수생들이 실습 도중 '비슷한 내용의 중 복'과 '허드렛일'을 경험하며 불만을 품게 된다는 분석 (Jang, 2017, p. 43; Moon, 2019, p. 514)을 견고히 한다.

(4) 불일치: 관리·감독의 부실

제도적 텍스트는 현장실습의 효율을 위해 강의자 대 비 연수생 비율(1명당 5명)과 출결관리 방안을 강조했 다(MCST, 2014, p. 21; 2015a, p. 6). 그러나 특정 운영기관은 이에 개의치 않고, 일대 다수의 비율로 실 습을 진행하며 관리·감독의 문제를 야기하고 있었다.

처음이랑 끝에 출석체크해서 이때 (연수생을) 무조건 체육관 실내 에 있게 했는데, 중간 중간 나갔다가 마지막에 들어와서 싸인(sign) 하고 실습영수증 끊는 분들을 봤어요. 아무래도 내용이자기가 배워 봤자 도움이 안 된다고 생각했기 때문에 밑에 카페(cafe)가서 있다 가 올라오는 거죠. $(\cdots)$ 실습을 시작하면 관리하시는 분들이 나가 버려요. 강사분이 한 번에 50 명을 다 볼 수 있는 능력이 안 되기 때 문에 “화장실 다녀올게요." 하면 강사입장에서 "가지마세요" 라고 막을 수 없으니까요(마코치).

마코치는 강사 혼자 실습을 주도하는 와중에 다수의 동태를 일일이 감시할 수 없다고 보았다. 더욱이 운영 대학의 관리자마저 세심한 주의를 기울이지 않기 때문 에, 연수자들이 실습 중 자리를 이탈한 뒤 인원체크 시 간에 맞춰 복귀하더라도, 이를 제어하지 못하는 애로사 항이 발생한다는 것이었다. 이러한 맥락에서 정부 및 산하기관은 2017년부터 연수생들의 비행을 미연에 방 지하고자 법령(KMGL, 2014.12.31)에 준해 불량태도 3회 적발 시, 응사자의 연수를 중단하는 조처를 강구했다.8)

8) 본 연구에서 확인된 바에 따르면, 위와 같이 개인들의 행보에 의해 자격제도가 보완되는 조정의 방향(개인 $\rightarrow$ 제도)은 이례적 인 반면, 개인이 제도에 순응하는 조정의 방향(제도 $\rightarrow$ 개인)은 지배적이었다. 이처럼 제도의 축으로 기울어진 관계와 조정은 제도적 문화기술지의 관점(Smith, 2005)이 간과한 현실의 장면이면서(Kim, 2013, p. 322), 자격제도를 운영하는 정부 및 산하기관이 텍스트 너머의 현실에 관심을 갖고, 불협화음 을 조율하려는 노력이 소홀했음을 반증하는 대목이다. 
하지만, 이제까지 해당조항에 근거한 연수중단의 실 례가 확인되지 않았다는 분석(Kim\& Kim, 2020, p. 829) 은 이어지는 참여자들의 진술과 함께, 특정 연수원의 관리·감독이 타성에 젖은 관료주의적 방식으로 운영되 어왔음을 대변한다.

불성실한 태도를 체크하시는 사람이 있긴 한데 $(\cdots)$ "아 어차피 이 건 시험 없이 듣는 거니까자기가 알아서 하겠지" 이런 식으로 넘어 가는 것 같습니다. 연수생이 항의하면 복잡해지니까 그런 복잡함을 아예 피하려고 하는...(서코치).

체크가 안돼요. 언제부터 이런 분위기였는지 몰라도 관리하거나 잡 으실 생각이 없어요. 좀 협조해달라는 식으로만 말씀을 하셔가지 고, 관리자가 관리할 의지가 없는데 관리가 될 리가 없죠. 반포기한 상태가 맞는 것 같아요(임코치).

(5) 조정: 참여동기 상실 및 의례절차로의 합리화 참여자들은 앞선 불일치 현상을 당면한 뒤, 실습에 대한 학습기대와 참여동기를 잃었다.

센터에 계신 선생님들이 수업하는 모습을 Observe(참관)하는 식 으로만 진행된다고 해가지고 현장에 접목된 교육을 받을 거라는 기 대는 없었어요. 그런데 아예 강의실에서 연수와 비슷하게 진행을 해 버리니까 없던 기대마저 사라졌죠(임코치).

유도장에 모아놓고 (신청종목은 보디빌딩인데) 골프 알려주고 있으 니까요 하면서도 이걸 내가 왜 해야 하나 이런 생각이 들고 좀 비판 적으로 말하면 공신력이 있는 국가에서 주는 자격증이 이것밖에 안 되나? (마코치).

선배들도 "그냥 있다 와라 시간 때우러 가는 거지 거기서 배우는 것 보다 차라리 자격증 용도로만 듣고 오라"고 합니다(서코치).

이들은 유관센터조차 참관만을 허가한다는 소식을 접해왔기 때문에, 애시당초 실습에 기대하는 바가 적었 다. 그러나 막상 허술한 운영을 겪어보니 “없던" 학습기 대와 참여의욕마저 잃고, 실습을 형식적이고 일회적인 의례절차로 여기게 되었다. 이와 같은 연수생들의 부정 적 인식(Jang, 2017; Moon, 2019)은 그간 정부 및 산하기 관이 현장실습의 '시행개요 및 계획'을 공지해온데 비 해(KMGL, 2014.07.07; MCST, 2015a), 그것의 실질적 운 영방책, 감독체계, 교육환경을 마련하는 데에는 관심 이 저조했음을 암시한다.

\section{2. 문제 틀의 확장: 자격제도의 작동기제}

규제적, 규범적, 담론적 매커니즘의 작동으로 견고 해진 제도의 배열(Lowndes \& Robert, 2013)이 개인들의 경험을 일련의 방향으로 유도하는 경향성(결)을 띠듯 이(Smith, 2005; Tak, 2018), 현행 자격제도의 저변에는 기능주의와 경험주의 페다고지가 작동하였고, 두 교육 논리는 연수생들이 경험한(할) 자격제도의 '실제들 (realities)'을 특정 방향(비연계적 교육내용, 비주체적 교육활동, 비체계적 교육운영)으로 견인하고 있었다.

\section{1) 기능주의 페다고지: 필기검정, 일반연수}

기능주의 페다고지(performance pedagogy)는 가르치 는 일을 과학적 검증을 거친 객관적 활동으로 이해하는 접근이다(Choi, 2004; Sidentop, 1983; Tinning, 1991). 이 러한 교육논리에 기초한 필기검정과 일반연수는 '이론 적 지식' 및 '전달의 효율(수단-목적)'을 강조함과 동시 에 그에 따른 한계(1),(2)를 수반하고 있었다(Table 8).

Table 8. performance pedagogy under written test and lecture

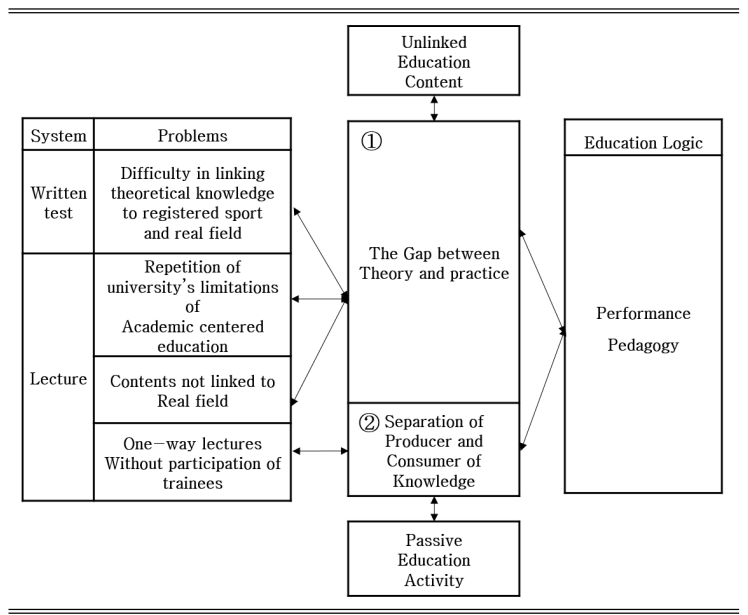

(1) 이론과 실제의 괴리: 비연계적 교육내용

기능주의 페다고지에서 실제의 개선은 이론의 적용 을 통해 이루어진다. 그동안 전문분야의 실제는 경험과 직관에 의존하여 운영되어온 까닭에(Schön, 1983), 합 리성, 보편성, 논리성을 담보한 이론을 처방함으로써, 문제를 해결할 수 있다고 본다(Lawson, 1990). 이러한 관점에서 이론은 실제와 구분되고, 과학적 검증을 거친 
객관적 이론은 실제의 주관적 경험보다 높은 가치를 지 닌 것으로 간주된다(Choi, 2009). 이와 같이 명제를 아는 것을 중시하는 논리는 이론을 인지한 후, 그것에 맞추 어 별다른 무리 없이 행위에 대입할 수 있다고 가정한 다(Ryle, 1949). 하지만, 기능주의 페다고지와 같이, 이 론적 처방이 변화무쌍한 실제현장에 깔끔하게 적용되 는 것은 아니다(Cassidy, Jones \& Potrac, 2016). 교수자가 실제와 결을 달리하는 이론적·사변적·정태적 명제를 전체인양 가르칠 때, 지식교육은 무기력해질 수밖에 없 기 때문이다(Hong, 2007).

현행 필기검정은 관련 학문과 법령을 효율적(획일 적)으로 배포하며(MCST, 2018b), 자격유형을 아우를 수 있다고 전제한다(Jung, 2019; Han, Shin \& Lee, 2018). 그러나 이러한 논리는 연수생들이 최소수준의 이론적 토대를 확보하는데 별다른 영향을 미치지 못했 다. 오히려 응시자들은 필기검정과정에서 '신청종목과 의 연관성' 및 '직무현장에서의 실효성'을 모색치 못한 채, 그것의 내용을 실제와 무관한 죽은 지식(Dewey, 1938; Whitehead, 1929)으로 치부하였다.

일반연수 또한 학문위주의 원론으로 다종다양한 신 청종목의 맥락을 망라한다고 가정한다(Kang, 2018; $\mathrm{Kim}, 2020)$. 하지만, 보편적 이론을 풀이하는 학문어의 재생은 구체적 관심사를 가진 지도자의 이해와 공감을 저해하기 때문에(Choi, 2009), 예비 스포츠지도자들은 일반연수의 비실제적 내용체계에 거부감을 표했다. 이 들은 이론을 실제현장과 하등 관계없는 것으로 재단하 며, 귀를 닫고 임의목적(“시간 때우기”)을 추구하였다.

이처럼 실제현장과 연계되지 못한 이론중심의 내용 체계는 오랫동안 지속되어온 고질적 사안이다(Choi, 1995). 하지만, 개편이후에도 동질적인 현상이 반복되 었는데, 이러한 사례의 축적은 명제적 지식이 종목 및 실무와 관계없이, 오직 학문과 이론의 미명하에 정당화 (Hirst, 1974; Peters, 1966)되는 논리를 대변한다. 아울 러, 2015년 개편자격제도의 내용체계는 현장실습(24시 간)에 비해 일반연수(66시간)의 영역이 높은 비중으로 할당되어있다(MCST, 2015a). 1990년대 자격제도의 비 율(3:1) 또한 이론에 편중된 전례를 참고하면(MSCT, 1993), 자격제도의 내용체계는 개편전후를 막론하고 [기초과학-응용과학-(현장)실습]의 위계를 반영한 기 능주의적 커리큘럼(Hughes, 1973; Schein, 1973)으로 구
성 및 공급되어왔음을 유추할 수 있다.

(2) 지식의 생산자와 소비자의 분리: 비주체적 교육활동 기능주의 페다고지는 이론과 실제사이 '적용'이라는 중간단계를 상정한다(Schön, 1983). 여기서 체육지도자 의 전문성은 학자들이 생산한 이론을 가지고 실제에 응 용하는 능력으로 여겨진다(Tinning, 1991). 즉 교수자는 이론을 전달하고, 학습자는 이를 현장에 대입하는 역할 을 담당한다(Choi, 2009). 이와 같이 지식의 생산자와 소 비자의 역할분업이 이뤄질 때, [이론-교수자-(전달)-학 습자-(적용)-실제]의 방향으로 능률적인 문제해결이 가 능하다고 본다(Korthagen, 2001). 이론의 습득 이후 그 것을 실제에 적용함으로써, 최소투입 최대효과를 산출 할 수 있다는 것이다. 하지만, 이론과 실제의 간극은 명 제의 송수신만으로 연접되기 어렵다. 추상적 이론을 구 체적 실제에 응용하기 위해선, 이질적인 두 점을 이어 바라볼 수 있는 '성찰의 역량'이 요청되기 때문이다 (Schön, 1983).

이상의 논리에 입각한 현행 일반연수의 경우, 강의 자당 다수의 연수생 비율이 만연하였고, 지식의 전달에 최적화된 교수법이 성행하였다. 연수자의 참여, 관심, 반응, 소통을 배제한 일방향적 강의법은 지식의 생산자 와 소비자의 역할을 양분하였다(Schön, 1987). 연수자 스스로 유용한 지식을 생산하지 못한다고 전제한 상태 에서 강의가 전개됨에 따라, 예비 스포츠지도자들의 학 습주체성이 무시되었다. 출결관리 또한 효율성을 높이 고자 이름순의 지정좌석제(MCST, 2015a)가 시행되었 다. 그러나 연수생의 신청종목과 무관한 좌석배치는 일 방향적 강의법 이외의 교수법 활용을 제약하며(Kang, 2018), 비주체적 교육활동의 풍토를 강화하였다.

종래의 일반연수는 이론의 효율적 전파를 통한 문제 해결(Problem solving)을 강조해온 나머지, 문제설정 (Problem setting)의 과정을 등한시해온 경향(Lawson, 1984)이 있었다. 불확실성, 불안정성, 불예측성이 농후 한 코칭현장(Lyle, \& Cushion, 2017; Purdy, 2018)에서 '문 제'는 지도자들에게 자연스레 주어지는 것이 아님에도 불구하고(Schön, 1983), 일반연수는 문제를 규정하기 위한 성찰(reflection)의 과정을 간과한 채, 보편적 이론 의 처방에 전념하며 독특한 사례(unique case)의 범주를 이탈해왔다(Schön, 1983, p. 41). 즉 예비 생활스포츠지 
도자들은 일반연수에서 객체적인 역할을 전담하며, 비 실제적 이론을 조달받아온 까닭에, 향후 정제된 이론으로 대응할 수 없는 엉망진창(mess)의 발산적 상황(divergent) 에서 혼란을 느끼게 될 가능성이 높았다(Schön, 1983, p. 43). 아닌 게 아니라, 이들은 문제를 해결하기 전, 해결해 야 할 문제가 무엇인지 규정지을 성찰역량을 함양하지 못 한 연유로, 이론의 적용과정에서 실제와의 괴리에 충격을 받고(Korthagen, 2001), 이제까지 암기해온 이론을 하얗게 잊어버리는 세척현상(washed-out)을 마주할 공산이 컸다 (Zeichner \& Tabachnick, 1981).

\section{2) 경험주의 페다고지: 구술·실기검정, 현장실습}

경험주의 페다고지(craft pedagogy)는 교육활동이 경 력자와 초심자의 경험적 상호작용으로 이뤼진다고 본 다(Gamble, 2010; Tinning, 1991; Tom, 1980). 이러한 교 육논리에 기초한 구술·실기검정과 현장실습은 '경력자 의 주관' 및 '운영의 자율성(비형식성)'을 강조함과 동 시에, 그에 따른 한계(1)를 동반하고 있었다(Table 9).

Table 9. craft pedagogy under oral \& skill and field work

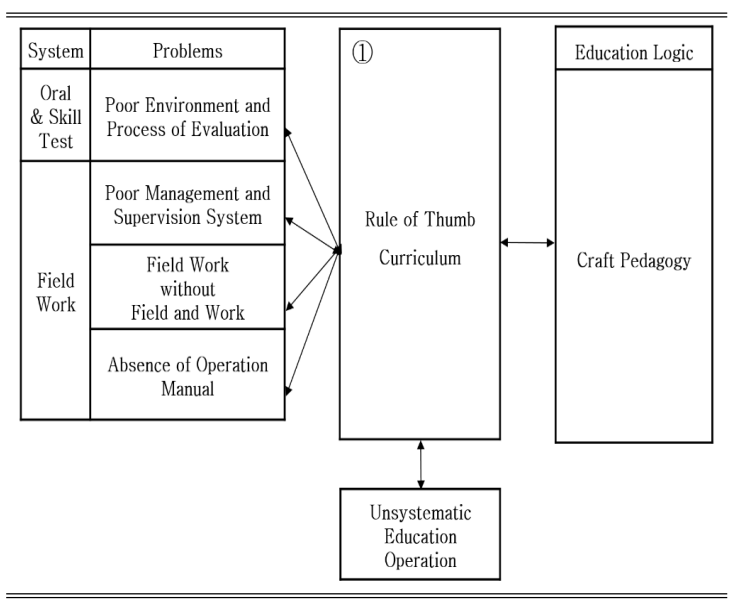

(1) 주먹구구식 교육과정: 비체계적 교육운영

경험주의 페다고지는 모종의 내용만 알고 있으면, 특별한 교육 없이도 가르치는 방법을 익힐 수 있다고 상정한다(Moore, 1970; Tinning, 1991). 이러한 접근은 도제교육과 같이, 상당부분을 경력자의 권위와 주관에 의존한다. 숙련된 경력자의 행동을 관찰·모방하며 실 천적 앎을 체화할 수 있지만(Lave \& Wenger, 1991), 운영 과정의 비형식성을 띠며 비교육적 행위를 허용하기도
한다(Eom, 2018).

상술된 논리에 기초한 현행 구술·실기검정은 전문 인으로 위촉된 시험위원(MCST, 2014)의 주관적 판단 으로 전개된다(Ahn, Kim \& Kim, 2016). 물론 정부 및 산하기관은 공정성의 강화를 계획했지만(KMGL, 2014.07.07; MCST, 2014), 일선에서는 시험위원의 주관에 치우친 평가의 공정성 문제가 재발하였다 (MCST, 2015b). 이외에도 비체계적인 환경 및 절차 (Gamble, 2010, p. 188; Tom, 1980, p. 320)로 인 해 뒷 순번(일자)의 연수생이 보다 수월하게 검정에 임 하는 형평성의 문제가 발생되었다. 이러한 한계는 응 시자들이 편법을 공공연한 관행으로 합리화할 빌미와 함께, 자격체제를 불신할 계기를 제공하였다.

현장실습 또한 경력자와의 상호작용을 장려함 (MSCT, 2014; 2015a)과 동시에, '비형식'의 그늘아 래 비교육적 사태들을 용인하고 있었다. 평가체제의 부재는 학습자가 '도달해야할 목표와 알아야할 내용 (Lee, 1996, p. 458)'의 결핍과 다르지 않기에, 연수 생들의 동기저하 및 불량태도(Jang, 2017)는 예정된 귀결이었다. 또한 관리·감독체계의 부실 및 운영기준 의 미비는 '연수생의 교육현장 이탈'과 '강사의 자의적 시간감축'을 허용하였고, “천차만별”의 내용 및 “중구 난방”의 방법을 용인하였다. 무엇보다 신청종목 및 직 무현장과 동떨어진 강의실 혹은 타 종목현장에서 실습 이 진행되는 경우가 부지기수였고, '훈련지도 주관 (KSPF, 2017, p. 13)'을 통한 '실무중심의 내용(pp. 409-410)'과 연관성이 희박한 (타 종목의) 동작위주 실습(MCST, 2018a)이 비일비재했다. 이러한 정황의 누적은 현장실습의 운영방식이 모종의 내용(동작)만 알고 있으면, 특별한 노력 없이도 자연스레 가르칠 수 있다는 경험주의적 논리(Choi, 2009; Tinning, 1991)에 입각하고 있음을 보여준다. 이와 같은 주먹구 구식 교육과정의 한계는 연수생들의 학습기대와 참여 동기를 상실시키고, 현장실습을 단순 자격취득을 위한 형식적 의례절차로 여기도록 종용하였다.

교수자와 학습자의 비형식적 역할수행이 전개되는 ‘환경의 구축여부'는 구성원사이 당연시 여겨진 기존 의 실천행위를 비판적으로 성찰하는데 영향을 미치는 동인이다(Handcock \& Cassidy, 2014). 하지만, 현장실습 의 경우 적절한 교육환경이 조성되지 않았다. 교육과정 
의 기본골격이 목표, 내용, 방법, 평가의 절차로 구성된 다는 분석에 기초할 때(Tyler, 1949), '모호한 목표', '변 질된 내용', '상이한 방법', '부재한 평가’체제는 현장실 습의 환경이 얼마나 방만한 상태인지 가늠시켜준다.

경험을 전수하는 당사자조차 자신의 체득해온 실천 적 앎의 정체를 자각하기 어려운 까닭에(Schön, 1983, p. 50), 강사들이 '내용을 아는 것'과 그 내용을 '가르치 는 방법을 아는 것'을 혼동하고(Shulman, 1986), 실습의 교수·학습과정을 단순히 현장에서 시간을 보내는 것으 로 오인할 여지가 충분했다(Gilbert \& Trudel, 2006). 따 라서 교육환경의 조성을 위한 목표, 내용, 방법, 평가체 계를 구축하고, 이를 담은 매개물(매뉴얼 혹은 가이드 라인)을 확립하지 않는 이상, 블랙박스와 같은 (실습)교 육의 과정이 구체화되기 요원할 뿐만 아니라(Gilbert \& Trudel, 2001; Kozulin, 2003; Locke, 1977), 기존의 풍토 (비체계적 교육운영)를 무비판적으로 재생산할 위험이 있다(Cushion, 2001).

\section{요약 및 제언}

본 연구의 목적은 2 급 생활스포츠지도사 자격취득 자들의 언어와 정부 및 산하기관 텍스트의 조정과정에 서 자격제도 내 교육과정의 실제를 이해하고, 그곳에 내재된 교육논리의 명암을 파악하는 것이었다. 참여자 들은 자격체제의 하위영역에서 조정(일치·불일치)을 거친 뒤, 시스템을 향한 의문, 불만, 수긍, 타협의 자기 합리화 과정을 겪었다. 자격제도의 근저에는 기능주의 페다고지와 경험주의 페다고지가 작동하였고, 두 교육 논리는 시스템 발전의 근원적 한계(비연계적 교육내 용, 비주체적 교육활동, 비체계적 교육운영)를 야기하 였다. 이러한 결과를 바탕으로 제언을 제시하면 다음과 같다.

첫째, 정부 및 산하기관은 기존의 메커니즘을 관성 적으로 고수하기보다, 다양한 교육논리(e.g., 기능적, 경험적, 반성적, 비판적, 해석적, 인문적 접근 등)의 허 와 실을 고찰하며(Choi, 2004; 2009, Tinning, 1991; 2002), 제도 발전에 유익한 관점을 선별해야 한다. 이를 위해 자격제도 내 교육과정의 실제와 논리를 '진단'하 는 후향의 관점이 활성화될 필요가 있다.
둘째, 필기검정의 내용체계는 신청종목 및 실무중심 으로 재구성되어야 한다. 이를테면 기존의 학문중심 골 격을 지양하고(e.g., 한국체육사), 다차원적 지식의 유 형(Shulman, 1986; Metzler, 2000)이 반영된 기준 (Cassidy, Jones \& Potrac, 2016, pp. 165-172)을 정립함으로써, 종목중심(e.g., 태권도체육사) 및 실무중 심(e.g., 효과적 회원 관리법)의 문항을 출제할 수 있다. 이러한 접근은 예비 코치들이 일선에 진출하기 전, 신청 종목 및 현장에 관한 기본지식을 함양하고(declarative knowledge), 이후 유사집단 및 상황에 적용이 유용하 며(procedural knowledge), 특정 문제에 왜 이러한 행동이 요구되는지(conditional knowledge)를 인식하도 록 조력할 수 있다(Metzler, 2000).

셋째, 구술·실기검정 환경 및 절차의 공정성 유지를 위한 감독 장치가 구비되어야 한다. 구술·실기검정의 속성상 시험위원의 재량적 평가기준으로 채점이 진행 되기 때문에(Ahn, Kim\& Kim, 2016, p. 470), 정부 및 산 하기관은 공정성의 훼손을 처벌하는 노력(MCST, 2015b)과 함께, 문제예방을 위한 실질적 관리체계의 수 립에도 관심을 기울여야 한다.

넷째, 강사교육 및 평가를 시행해야 한다. 제도적 텍 스트는 다양한 교수법의 개발 및 활용을 요구해왔다 (MCST, 2014; KSPF, 2017). 하지만 강사들은 제도의 요 청을 외면한 채, 일방통행의 교수법을 고수하였고, 이 로 인해 연수생들이 교육에서 소외되는 현상이 초래되 었다. 따라서 정부 및 산하기관은 강사교육을 통해 학 습자의 참여촉진에 유용한 교수모형을 공유하고, 강사 선정 및 평가항목에 교수법의 활용여부를 반영함으로 써 강사들의 인식재고를 독려할 필요가 있다.

다섯째, 현장실습의 평가체계 및 운영기준이 확립되 어야 한다. 일례로 교수자와 학습자사이 비형식적 경험 의 교류를 공식화하거나 모형화해온 멘토링 분야의 범 례와 같이(Chambers, 2015; Griffiths, 2013; Lyle, \& Cushion, 2017), 현장실습의 목표, 내용, 방법, 평가체계 를 정립함으로써, 실습공간에 위치한 것만으로 모종의 효과가 깃든다는 ‘오해'와 강사별 상이내용 및 방법이 실행되는 '혼란'을 해소해야 한다.

여섯째, 현장실습 운영의 허브(hub)를 대학부속기관 에서 개별 종목협회로 재설정하는 구조개편(Kwon, 2017, p. 59)이 검토되어야 한다. 이를 통해 '현장'과 '실 
무'의 타당성을 확충하고, 강사의 '전공종목'과 연수생 의 '신청종목'의 일치성을 높여야 한다. 대학부속기관 이 현장실습의 운영주체로 존속될 경우, 연수생들이 유 사종목기관으로 이동하거나, 이마저도 허용되지 않아 대학 체육관 혹은 강의실에서 (타 종목의) 동작교육을 제공받는 문제(MCST, 2018a, p. 181)가 재발될 공산이 크다.

모든 경험의 조각들이 교육적 경험으로 이어지지 않 듯이(Dewey, 1938), 연수생들이 자격제도에 참여한다 는 사실, 그 자체만으로 전문성의 증진을 기대하기 어 려울 것이다. 정녕 정부 및 산하기관이 '장롱 속 자격증 발급(Eun, 2017)'이 아닌, 온전한 자질을 갖춘 '체육전문 인의 양성'을 바란다면, 그에 합당한 교육논리가 내재 된 프레임워크와 커리큘럼을 제공할 필요가 있다.

자격증을 땄으니 어느 정도 전문성을 가지고 있다고 인정이 되어야 하는데, 이런 식으로는 전혀 이뤄질 수 없다고 봐요. 사람들에게 “내 가 이자격증을 따서 이제가르칠 수 있어요"라고 몇 명이나 말할 수 있을까요? 교육과정이 이렇게 부실한데, 이 사람들이 (현장에) 나가 서제대로 못하는 것은 당연한 결과죠. 생활체육지도자 자격증을 국 가기관이 발급하는 거면 신뢰를 쌓을 수 있도록, 많이 개선되어야 한다고 생각해요(임코치).

\section{참고문헌}

Ahn, J. H., \& Kim, M. Suk., \& Kim, S. H. (2016). A Study on Cognition of Applicants for the Sports Coaching Certificate System: Focusing on the Practical and Oral Certifying Test for the Sports Coaching Certificate. Journal of Digital Convergence. 14(7), 461-473.

Campbell, M., \& Gregor, F. (2002). Mapping social relations: A primer in doing institutional ethnography. University of Toronto Press.

Cassidy, T. G., Jones, R. L., \& Potrac, P. (2016). Understanding sports coaching: The social, cultural and pedagogical foundations of coaching practice(3th ed). Abingdon: Routledge.

Chambers, F. C. (2015). Mentoring in physical education and sports coaching. Abingdon: Routledge.

Chin, J. S., Kim, H. S., \& Lee, Y. K. (2015). The
Relationships among Expertise, Job Satisfaction and Happiness of Leisure Sports Instructor. The Korean Journal of Sport. 13(2), 191-202.

Cho, M. H. (2008). A Review of the National Coaching Certification for the Professionalization of Sport Coaches. Journal of Sport and Leisure Studies. 3(1), 51-61.

Cho, M. H. (2016). A Review of National Sports Coaching Certification Institution. Korean Society For The Study Of Physical Education 20(4), 161-174.

Cho, M. H., \& Kwon, W. D. (2011). Are the National Certifications of Sport and Recreation Moving into Professionalization?. Korean Society For Sport Management 16(1), 15-25.

Choi, E C. (2004). Who is the Most Desirable Physical Education Teacher?: The Dominant Trends of Physical Education Teacher Education and Future Tasks. Korean Journal of Sport Pedagogy 11(2), 25-49.

Choi, E C. (2009). The Education of Sport professional. Gyeonggi: Life \& Power Press.

Choi, E C. (2015). National Standatds for sport Coaches: Quality coaches, Quality Sport. Seoul: Rainbow books.

Choi, E, C. (2018). What is coaching. Seoul: Rainbow books. Choi, E. C. (1995). Developing Strategies for Effective Professional Training Programs for Sport-for-All Instructors. The Journal of Korean Education. 22, 197-224.

Choo, J. Ho. (2017). Development and Applicability of Competency Model Evaluation Indicator according to the Modification of Physical Education Instructor Qualification. The Korean Journal of Sport. (15)3, 639-648

Cushion, C. (2001). The coaching process in professional youth football: An ethnography of practice. Unpublished Doctoral dissertation, Brunel University.

Daniel, Y. (2004). The discursive effects of policy texts: An institutional ethnography of funding special education in Ontario. dissertation, York University, Toronto.

DeVault, \& McCoy (2006). Institutional ethnography: Using interviews to investigate ruling relations. In Dorothy E. Smith, (Eds). Institutional ethnography as practice (pp.15-44). Lanham, MD: Rowman \& Littlefield Publishers.

DeVault, M. L. (2006). Introduction: What is institutional ethnography?. Social problems, 53(3), 294-298. 
Dewey. J. (1938). Experience and Education. Jone Dewey: The Later Work. Carbondale \& Edwardsville: Southern Illinois University Press.

Eisner, E. W.(1979). The educational imagination: on the design and evaluation of school programs. NY: Macmillan.

Eom, T. D. (2018). Educational cooperation and competition of great scholars and artists. Seoul: Hankook publishing.

Eramus Programme of the European Union(2017). European Sport Coaching Framework. CI: Human Kinetics.

Eun, H. K. (2017). Exploring the Necessary Factors for Improvement of Leadership Ability of Sports Leaders. The Korean Journal of Sport. 15(3), 169-179.

Gamble, J. (2001). Modelling the invisible: The pedagogy of craft apprenticeship. Studies in continuing education, 23(2), 185-200.

Gilbert, W. D., \& Trudel, P. (2001). Learning to coach through experience: Reflection in model youth sport coaches. Journal of teaching in physical education, 21(1), 16-34.

Gilbert, W. D., \& Trudel, P. (2006). The coach as a reflective practitioner. In Jones, R, L (Eds.). The sports coach as educator (pp. 98-112). NY: Routledge.

Griffiths, M. (2011). Mentoring as a professional learning strategy. In K. Armour (Eds), Sport Pedagogy (pp. 299-311). London: Pearson Education.

Han, D. S., Shin, W. K., \& Lee, J. Y. (2018). Analyzing Item and Exploring Orientation in Sport Pedagogy Examinations in the Qualification. CNU Journal of Educational Studies. 39(1), 231-254.

Handcock, P., \& Cassidy, T. (2014). Reflective practice for rugby union strength and conditioning coaches. Strength \& Conditioning Journal, 36(1), 41-45.

Hirst, P. H. (1974). Knowledge and curriculum. London: Routledge \& Kegan Paul.

Hong, E. S. (2007). concept of education. Gyeonggi: kyoyookbook.

Hughes, E. (1973). Higher education and the professions. Content and Context: Essays on College Education, NY: McGrawHill.

International Council for Coaching Excellence. (2013). International Sport Coaching Framework(Version 1.2). CI: Human Kinetics.

Jang, H. J. (2017). Current Status and Improvement of the
Certified Sport Instructor Field Practicum: Perspectives from Critical Discourse Analysis. Unpublished master thesis. Keimyung University. Daegu.

Jung, D. J. (2019). Improvement Plan of Physical Education Leader Qualification Framework. The Journal of Educational Development 39(2), 379-391.

Jung, H. W., Lee, C. H \& Lee, G. S. (2019). Critical Review on Sports Coach Qualification System: Focus on the Concept of Desirable Sports Coach and Coach Standards and Competency. The Korean Journal of Physical Education, 58(3), 143-157.

Jung, M. S, (2000). Effects Of Sport and Leisure Leaders' Satisfaction with their jobs and Organizations on Turnover. Korean Journal of Sport Management 5(1). 29-46.

Jung. H. W. (2020). Dream' to train 'sports education experts'. In Korea sport pedagogy (Eds). What will be the direction of future sports education and the training of experts?. (pp. 146-155). Seoul: Rainbow books.

Kang, B. S. (2018). Exploration of perception changes after first-grade elite sport instructor training program. Korean Society For The Study Of Physical Education 23(1), 167-180.

Kim, D. H. (2020). Grounded Theory Approach for Improving National Qualification Program of Life Sports Instructor. The Korean Journal of Physical Education, 59(4), 113-129

Kim, D. H., \& Kim, D. W. (2020). Exploring the Development Plan through the Practical Training Operational Examples of the Second-level Life Sports Instructor. Korean Journal of Sports Science 29(4), 819-838.

Kim, H. S \& Lee, J. H. (2003). The Factors Affecting on the Occupational Socialization of Sport Instructors. Journal of Sport and Leisure Studies. 19(1), 335-353.

Kim, H. S. (2004). A Conflict and Turnover of Sport Instructors. The Korea Journal of Physical Education. 43(3). 365-373.

Kim, H. S. (2005). An Expertise of Sport Instructors. Journal of Sport and Leisure Studies. 24, 17-29.

Kim, H. S. (2011). The Relationship Between Pedagogical Content Knowledge and Expertise of Leisure Sports Instructors. Journal of Sport and Leisure Studies. 43, 13-25.

Kim, I. S. (2013). Institutional Ethnography: Why Another Methodology?. Korean Journal of Social Welfare, 65(1), 299-324. 
Kim, J. H., \& Chung, M. S. (1996). A Study on the job participation and specialized capacity of Sports and Leisure Leaders. Journal of Sport and Leisure Studies, 5, 79-85.

Kim, S. H \& Kim, J. H. (2017). A Study on Implementation of Sport Pedagogy Subject for the Sports Coaching Qualification System. The Korean Journal of Physical Education, 56(2), 259-270.

Kim, W. K (2017). Study on the Development of Expertise the Instructors to Promote Life Sports. Journal of the Korea Entertainment Industry Association 11(6), 153-163.

Korea Ministry of Government Legislation. (2014.07.07). Article 4 of National Sport Promotion legislation Enforcement Rules 10.

Korea Ministry of Government Legislation. (2014.07.07). Article 3 of National Sport Promotion legislation Enforcement Rules 11.

Korea Ministry of Government Legislation. (2014.10.28.). School Sport Promotion legislation Enforcement Rules 3.

Korea Ministry of Government Legislation. (2014.12.31.). Article 2 of National Sport Promotion legislation Enforcement Rules 14.

Korea Ministry of Government Legislation. (2019.12.10). Article 2 of National Sport Promotion legislation Enforcement Rules 10.

Korea Sport Promotion Foundation. (2017). Class-2 Life Sports Coach Training Textbook.

Korthagen, F. A. (2001). Linking practice and theory: The pedagogy of realistic teacher education. NJ: Lawrence Erlbaum Associates.

Kozulin, A. (2003). Psychological tools and mediated learning. Vygotsky's educational theory in cultural context, 15-38.

Kwon. Y. T. (2005). A study the Improvement Plan to Cultivation System for Training of Sport \& Leisure. Journal of Sport and Leisure Studies 23, 9-20.

Kwon. Y. T. (2017). A Study on the Improvement of Sports Leader Qualification System through Present Training Condition and Trend Analysis : Based on Sport and Leisure Field. Journal of Sport and Leisure Studies 70, 49-62.

Lave, J., \& Wenger, E. (1991). Situated learning: Legitimate peripheral participation. Cambridge university press.

Lawson, H. A. (1990). Beyond positivism: Research, practice, and undergraduate professional education. Quest, 42(2), 161-183.

Lee, H. W. (2000). Internalization of Subject Matter. Asian Journal of Education. 1(1), 249-271.

Lee, K, H., \& Yoo, B. In. (2001). A Study on Community Physical Activity Leaders' Perceptions on Vocational Environment and Condition. Korean Society For Sport Management. 6(2), 25-36.

Locke, L. F. (1977). Research on teaching physical education: New hope for a dismal science. Quest, 28(1), 2-16.

Lowndes, V., \& Roberts, M. (2013). Why institutions matter: The new institutionalism in political science. Basingstoke: Macmillan International Higher Education.

Lyle, J., \& Cushion, C. (2017). Sport coaching concepts: A framework for coaching practice. NY: Taylor \& Francis.

McCoy, L. (2006). "Keeping social organization in view: A data analysis in institutional ethnography”, In D. E. Smith (Eds,), Institutional Ethnography as practice. Calif: Walnut Creek.

Metzler, M. (2000). Instructional models in physical education. Needham Heights, MA: Allyn \& Bacon.

Ministry of Culture, Sports and Tourism. (2013.07.01.). Anew system of qualification for Sport coach will be implemented from 2015.

Ministry of Culture, Sports and Tourism. (2014). Explanation on the Reorganization of the Qualification System for Sport Coach.

Ministry of Culture, Sports and Tourism. (2015a). Training Operating Guidelines for Sport coach.

Ministry of Culture, Sports and Tourism. (2015b). Efforts to strengthen fairness in the qualification system for sports coach.

Ministry of Culture, Sports and Tourism. (2018a). Basic Plan for National Sports Promotion.

Ministry of Culture, Sports and Tourism. (2018b). A Study on the System Improvement for the Establishment of the Qualification System for sport coach.

Ministry of Culture, Sports and Tourism.. (1993). a collection of laws and regulations on sports.

Moon, B, H. (2019). Improvement Plan of Consumer-centered Education Environment based on Experience of Field Practice of Preliminary Sport Leader. The Korean Journal 
of Sport 2019, 7(2), 511-517.

Moore, W. E. (1970). The professions: Roles and rules. Russell Sage Foundation.

National Association for Sports and Physical Education. (2006). National standards for sport coaches: Quallity coaches, quality sports(2nd ed.). Reston, VA: American Association of Physical Education, Recreation and Dance.

Nichols, N., \& Griffith, A. I. (2009). Talk, texts, and educational action: an institutional ethnography of policy in practice. Cambridge Journal of Education, 39(2), 241-255.

Oh, J. S. (2000). A Direction on The Cultivation System and Policy for "Sport for All” Leaders. Journal of Sport and Leisure Studies 13, 763-773.

Oak, J. S. (2007). Reformation of physical education leader certification program. KINESIOLOGY. 9(2), 79-96.

OhmyNews. (2018.12.05). The sadness of swimming instructors who work overtime enduring low body temperature in disinfection.

Park, J. H \& Park, S. J (2008). Proposals for the Improvement of the National Sports and Exercise Instructor Qualification System. Journal of Korean Society of Sport Policy. 11, 37-46.

Park, J. H \& Park, S. J (2014). A Study in Improving the Qualification Policy for Sports Instructors. Journal of Korean Society of Sport Policy, (12)1, 77 85.

Patton, M. Q. (2015). Qualitative evaluation and research methods(4th ed). CA: Sage.

Peacock, D. (2017). Institutional Ethnography, Critical Discourse Analysis, and the Discursive Coordination of Organizational Activit.. Reid, J., \& Russell, L. (Eds). In Perspectives on and from Institutional Ethnography (pp. 91-106). Bingley: Emerald Publishing.

Peters, R. S. (1966). Ethics and education. London: Allen \& Unwin.

Purdy, L. (2018). Sports coaching: The basics. NY: Routledge. Ryle, G. (1949). The Concept of Mind. NY: Barnes \& Noble.

Ryu, H. K. (1998). an Introduction of Educational Epistemology. Gyeonggi: kyoyookbook.

Schein, E. (1973). Professional Education. NY. McGraw Hill.

Schön, D. A. (1979). Generative metaphor: A perspective on problem-setting in social policy. Metaphor and thought, 2,
137-163.

Schön, D. A. (1983). The Reflective Practitioner: How Professionals Think In Action. NY: Perseus Books Group. Schön, D. A. (1987). Educating the reflective practitioner. NY: Perseus Books Group.

Sea, Y. H, Kim, K, Shin, J. H (2014). A Study on Improving the Treatment of Non-regular Physical Education Instructors. The Korean Society Of Sports Science. 23(5), 13-29.

Shim, S. S. (2012). Influence of Professionalism on Job Embeddedness and Job Burnout of Life Time Sports Instructors. The Korean Journal of Physical Education, 51(1), 323-332.

Shon, S. J., Choo, J. H., Nam, K. Y., Shin, J. H., Nam, S. N \& Cha. K. S. (2016). Directions for the Labor Condition Improvement and Status Enhancement of Physical Education Directors. The Korean Journal of Physical Education, 55(4), 1-12.

Shulman, L. S. (1986). Those who understand: Knowledge growth in teaching. Educational researcher, 15(2), 4-14.

Siedentop, D. (1983). Developing teaching Skills in Physical education. Mountain View, CA: mayfield.

Smith, D. E. (2005). Institutional ethnography: A sociology for people. Maryland: Altamira press.

Sport and Recreation New Zealand. (2006). Coach development framework. Wellington: Astra Print.

Talbot, D. (2017). The dialogic production of informant specific maps. Reid, J., \& Russell, L. (Eds). In Perspectives on and from Institutional Ethnography (pp. 1-28). Bingley: Emerald Publishing.

Tak, M. H., (2018). Three conceptual tools for studying sports-related social/policy institutions: Costs, paths and grains. Korean Society for the Sociology of Sport 31(1), 171-196.

Tinning, R. (1991). Teacher education pedagogy: Dominant discourses and the process of problem setting. Journal of teaching in physical education, 11(1), 1-20.

Tinning, R. (2002). Toward a "modest pedagogy": Reflections on the problematics of critical pedagogy. Quest, 54(3), 224-240.

Tom, A. R. (1980). Teaching as a moral craft: A metaphor for teaching and teacher education. Curriculum Inquiry, 10(3), 
317-323.

Tyler, R. W. (1949). Basic principles of curriculum and instruction. Chicago: University of Chicago press.

Walby, K. (2005). 'Doing surveillance studies' in institutional ethnography and surveillance studies: An outline for inquiry. Survellance and Society, 3(2/3), 158-172.

Whitehead. A. N. (1929). The Aims of Education. NY: Macmillan.
Won, Y. S., Lee, K. H., \& Yoo, Y. S., (2001). A Study of Community Sports Program Leaders' Working Conditions and Job Satisfaction. Korean Society For Sport Management 6(1), 77-91.

Zeichner, K. M., \& Tabachnick, B. R. (1981). Are the effects of university teacher education 'washed out' by school experience?. Journal of teacher education, 32(3), 7-11.

\title{
2급 생활스포츠지도사 자격검정제도의 조정과정 분석을 통한 조직된 실제와 교육논리 탐색
}

\author{
유주영 \\ 서울대학교, 석사
}

[목적] 본 연구의 목적은 2급 생활스포츠지도사 자격취득자들의 경험적 언어와 정부 및 산하기관의 제도적 텍스트의 조정과정에서 교육과정의 조직된 실제를 이해하고, 그곳에 내재된 교육논리의 명암을 파악하는 데 있다. [방법] 이를 위해 Smith(2005)의 제도적 문화기술지(institutional ethnography)를 방법으로 채택하였 다. 참여자는 2015년 개편이후 검정에 임한 7명의 자격취득자로 선정되었다. 자료는 현지자료와 반-구조화된 면담을 통해 수집되었다. 취합된 자료는 사회적 조직도 그리기(mapping social organization) 방법으로 분석 되었다. [결과] 첫째, 참여자들은 필기검정, 구술·실기검정, 일반연수, 현장실습 영역에서 불일치 현상을 당면 한 뒤, 자격시스템을 향한 의문, 불만, 수긍, 타협의 (자기)합리화 과정을 겪었다. 둘째, 현행 자격제도의 근저 에는 기능주의 페다고지(performance pedagogy)와 경험주의 페다고지(craft pedagogy)가 작동하였고, 두 교 육논리는 시스템 발전의 근원적 한계(비연계적 교육내용, 비주체적 교육활동, 비체계적 교육운영)를 야기하였 다. [결론] 자격체제의 진일보를 위해 정부 및 산하기관은 기존의 메커니즘을 관성적으로 고수하기보다, 다양 한 교육논리의 허와 실을 선별해야 함을 제언하였다. 이러한 결론은 향후 체육전문인 양성을 위한 국가단위 프레임워크(framework) 구축에 유효한 함의를 제공할 것으로 기대된다.

주요어: 자격검정제도, 교육과정, 조정, 조직된 실제, 교육논리 